\title{
MULTIPLE REGRESSION MODELING OF NATURAL RUBBER SEISMIC- ISOLATION SYSTEMS WITH SUPPLEMENTAL VISCOUS DAMPING FOR NEAR-FIELD GROUND MOTION
}

\author{
Mohammad H. ALHAMAYDEH ${ }^{\mathrm{a}}$, Samer A. BARAKAT ${ }^{\mathrm{b}}$, Farid H. ABED ${ }^{\mathrm{a}}$ \\ ${ }^{a}$ Department of Civil Engineering, American University of Sharjah, PO Box 26666, \\ Sharjah, United Arab Emirates
${ }^{b}$ Department of Civil \& Environmental Engineering, University of Sharjah, PO Box 27272, Sharjah, \\ United Arab Emirates
}

Received 16 Jul. 2011; accepted 6 Jan. 2012

\begin{abstract}
This work presents the development and implementation of the Multiple Regression Analysis (MRA) model to Seismic-Isolation (SI) systems consisting of Natural Rubber Bearings and Viscous Fluid Dampers subject to Near-Field (NF) earthquake ground motion. A model representing a realistic five-story base-isolated building is used. Several damper properties are used in creating an array of feasible combinations for the SI system. Two ensembles of seven NF earthquake records are utilized representing two seismic hazard levels. The key response parameters investigated are the Total Maximum Displacement, the Peak Damper Force and the Top Story Acceleration Ratio of the isolated structure compared to the fixed-base structure. Mathematical models for the key response parameters are established via MRA. The MRA models produced acceptable results with significantly less computation. This is demonstrated via a practical example of how the MRA models would be incorporated in the design process, especially at the preliminary stages.

Keywords: seismic; seismic-isolation; multiple regression; supplemental viscous damping; near-field.

Reference to this paper should be made as follows: AlHamaydeh, M. H.; Barakat, S. A.; Abed, F. H. 2013. Multiple regression modeling of natural rubber seismic-isolation systems with supplemental viscous damping for near-field ground motion, Journal of Civil Engineering and Management 19(5): 665-682. http://dx.doi.org/10.3846/13923730.2013.799089
\end{abstract}

\section{Introduction}

Seismic-Isolation (SI) with and without supplemental damping for energy dissipation has proven to be an effective method of control for structures during seismic events. Many types of isolators exist commercially today, which are capable of supplying the system with significant added damping such as the HighDamping Rubber (HDR) bearings and Lead-Rubber Bearings (LRB). On the other hand, other types have little damping to offer such as the Natural Rubber Bearings (NRBs) (Skinner et al. 1993; Kelly 1997; Naeim, Kelly 1999).

Jangid (2005) investigated the optimum use of the Friction Pendulum System (FPS) isolators for Near-Field (NF) earthquake motion in multi-story buildings. He evaluated the response of the system to six records of NF earthquakes and derived the optimum friction coefficient of the FPS. That was done such that it minimized both the top floor acceleration and the total horizontal sliding distance.
It was concluded that the optimum friction coefficient for FPS for NF earthquake motions is in the range between 0.05 and 0.15. Matsagar and Jangid (2005) also investigated the use of viscoelastic dampers as connectors between seismic-isolated buildings and the adjacent buildings whether seismic-isolated or fixedbase buildings. It was concluded that the introduction of the dampers enhances the performance of the seismic-isolated buildings and reduces the chances of pounding between buildings.

Typical Far-Field (FF) response of seismic-isolated structures is manageable, compared to the high demands of a NF event (Rodriguez-Marek 2000; Jangid, Kelly 2001). Other researchers have also investigated the effectiveness of supplementing LRB isolators with dampers in controlling the NF responses of Reinforced Concrete (RC) buildings (Chopra, Chintanapakdee 2001; Macrae et al. 2001; Makris, Black 2004). With high-velocity pulses and high displacement demands, many NF situations require impractical isolator bearing dimensions and

Corresponding author: Mohammad AlHamaydeh

E-mail: malhamaydeh@aus.edu 
designs. In such situations, utilizing HDR bearings, LRB or FPS alone is not the best engineering solution. Consequently, supplemental damping is needed to reduce the horizontal displacement demands, otherwise structural integrity could potentially be jeopardized (Providakis 2008, 2009). The combined isolation system of HDR or LRB with viscous dampers seem to work well in the NF regions, where the ground shaking characteristics are capable of producing pulses with velocity of $0.5-1.5 \mathrm{~m} / \mathrm{s}$ and durations of 1-3 s. Unfortunately, this combined system does not perform desirably in moderate or strong FF events due to the secondary forces produced by the dampers and their complex coupling effects (Providakis 2008), as well as the higher modes effects.

When faced with the challenge of limiting the Total Maximum Displacement $\left(D_{\mathrm{TM}}\right)$ to practical limits, especially in NF sites, often times the designer would rely on Viscous Fluid Dampers (VFDs). The basis of this practice is the capability of velocitydependent devices to provide higher damping levels without significantly stiffening the structure as compared to displacement-dependent (hysteretic) damping devices. Moreover, since the peak velocities and peak displacements are out-of-phase of each other, the device-produced forces at the seismic-isolation interface are constrained to manageable levels.

The state-of-the-practice involves carrying out preliminary calculations and analyses using typical HDR bearings or LRB which provide a moderate amount of hysteretic damping. No supplemental dampers are used in these initial calculations. These preliminary calculations could readily conclude whether or not supplemental damping would be required. An example of such exercise is presented in a subsequent section. Once supplemental damping is deemed necessary, many designers would prefer utilizing the linear behavior of NRB isolators combined with the supplemental damping provided by VFDs; the use of such a system often results in additional uniformity to the story forces induced in the superstructure due to the reduced out-of-phase velocity and displacement peak responses. This system has also been used in many projects in the USA and Japan (Hussain et al. 1993; Hussain 1994; Hussain, Retamal 1994; Hussain, Al Satari 2007a, b, 2008; Al Satari, Abdalla 2009; AlHamaydeh, Hussain 2010; Kani, Nishikawa 2010).

This study utilizes Multiple Regression Analysis (MRA) to model the behavior of the combined NRBVFD system under dual-level ensembles of NF earthquake motions. The overall SI system performance is evaluated for different supplemental damping properties. For that purpose, a Multi-Degree-Of-Freedom (MDOF) system is adopted and described in subsequent sections. The key response parameters considered are the $D_{\mathrm{TM}}$, the Peak Damper axial Force $\left(P_{\mathrm{DF}}\right)$ and the Top Story Acceleration Ratio (TSAR) of the isolated structure compared to the fixed-base structure. The top floor acceleration was used as a direct measure of the isolation system efficiency. By comparing the top floor acceleration of the isolated structure to the top floor acceleration of the benchmark fixedbase structure, the efficiency of the isolation system can be quantified. Consequently, this parameter was selected as a major performance descriptor. However, attempting to minimize the TSAR without monitoring other parameters could potentially result in excessive and unrealistic $D_{\mathrm{TM}}$ demands. Consequently, the $D_{\mathrm{TM}}$ as well as the base shear $\left(V_{\mathrm{b}}\right)$ are considered as key performance criteria. For design purposes, the most efficient system can later be selected based on the trade-off between minimizing the floor accelerations on one hand and minimizing the $D_{\mathrm{TM}}$ and $V_{\mathrm{b}}$ on the other.

\section{Model description}

\subsection{The damping system}

The fluid viscous damper force-velocity behavior is governed by the mathematical expression described in Eqn. (1):

$$
F_{\mathrm{D}}=c \operatorname{sgn}(\dot{v})|\dot{v}|^{\alpha}
$$

where: $F_{\mathrm{D}}$ is the damper force $(\mathrm{kN}), c$ is the damping coefficient $\left(\mathrm{kN}-(\mathrm{s} / \mathrm{m})^{\alpha}\right), \dot{\nu}$ is the damper extensional velocity $(\mathrm{m} / \mathrm{s}) ; \alpha$ is the velocity exponent (for a linear damper, $\alpha=1$ ) and sgn denotes signum function describing the velocity sign. In seismic applications, nonlinear dampers with damping exponent less than unity are preferred due to their softening or yielding nature at higher velocities and the stiffening effect at lower velocities. This nonlinear characteristic results in significant reduction of base displacement in response to strong ground shaking, particularly in NF situations. Furthermore, it puts practical limitations on the amount of force transferred to the structural elements. Although some manufacturers can produce dampers with $\alpha$ value as low as 0.1 , the typically used values range from 0.4 to 0.7 .

In this study, the damping exponent values considered range from 0.4 to 1.0 with intermediate values equally spaced at 0.15 intervals. Except when $\alpha=1$, the damper elements are behaving nonlinearly and they are the only part of the model that could exhibit nonlinearity. The superstructure of an isolated structure is typically expected to remain near-elastic throughout significant seismic events, which justifies the linear analysis here. The considered values for the damping coefficient c range from 175 to $525 \mathrm{kN}$ $(\mathrm{s} / \mathrm{m})^{\alpha}$ with intermediate values equally spaced at intervals of $88 \mathrm{kN}-(\mathrm{s} / \mathrm{m})^{\alpha}$. The five different $c$ and $\alpha$ values are used to generate 25 combinations to be investigated in the analysis. 
Table 1. MDOF system parameters (Kelly et al. 1987)

\begin{tabular}{lcccc}
\hline Story & $\begin{array}{c}\text { Mass } \\
(\mathrm{kg})\end{array}$ & $\begin{array}{c}\text { Stiffness } \\
(\mathrm{kN} / \mathrm{m})\end{array}$ & Mode & $\begin{array}{c}\text { Period of } \\
\text { vibration }(\mathrm{s})\end{array}$ \\
\hline 5 & 5897 & 19,059 & 6 & 0.048 \\
4 & 5897 & 24,954 & 5 & 0.057 \\
3 & 5897 & 28,621 & 4 & 0.073 \\
2 & 5897 & 29,093 & 3 & 0.115 \\
1 & 5897 & 33,732 & 2 & 0.313 \\
Isolation & 6800 & 232 & 1 & 2.500 \\
system & & & & \\
\hline
\end{tabular}

\subsection{SAP2000 modeling of the MDOF system}

To include higher modes influence in the base isolation behavior, MDOF systems should be considered. The numerical analysis of the proposed MDOF system was conducted using the commercial finite element code SAP2000 (CSI 2010). For this study, a simple lumped-mass stick model is used to represent a five-story base-isolated building which has been introduced by Kelly et al. (1987). The masses in the SAP2000 model are assigned as lumped (concentrated) and the stick model utilizes generic frame elements. Table 1 illustrates the material properties including the mass and stiffness at each story for the adopted system, as well as the modal information for the first six vibration modes of the MDOF system. The building structural parameters and isolator properties are proportioned such that the fundamental period of vibration is $2.5 \mathrm{~s}$ and the modal damping is $5 \%$ of critical. The MDOF system has been modeled in three different configurations (boundary conditions) for comparison: (1) fixed base, (2) isolated without dampers, and (3) isolated with dampers. Figure 1 shows the SAP2000 model used to model the MDOF system. To account for accidental torsion in the superstructure that would be produced by the most disadvantageous location of eccentric masses, the story masses are shifted by $5 \%$ of the typical diaphragm dimension to create rotational masses.

It should be emphasized that the proposed SAP2000 stick (mass-spring) model is a replica of the original model proposed by Kelly et al. (1987), and has the same natural frequencies (periods) as presented in Table 1. The natural frequencies produced by the SAP2000 model are matching their counterparts from the original model, which validates the dynamic analysis results performed by the SAP2000 model.

\subsection{The ground excitation}

There are different parameters to characterize and quantify earthquake demand and damage potential. The Peak Ground Acceleration (PGA) and Peak Ground Velocity are good examples of such parameters. Although they are naturally related to ground shaking intensity, unfortunately, both have limitations (a)

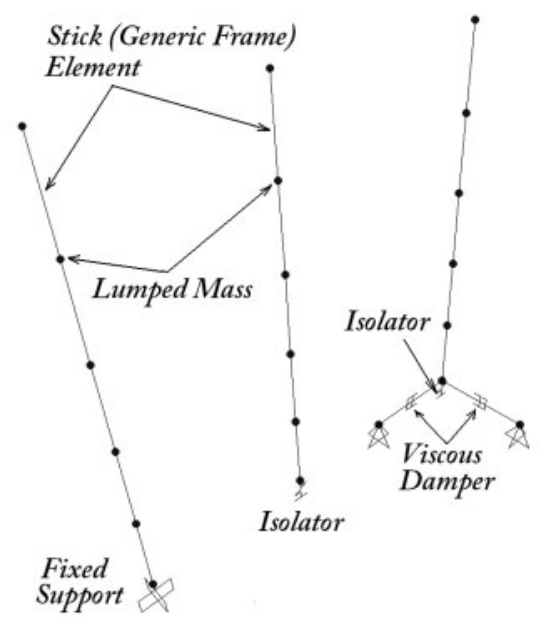

(b)

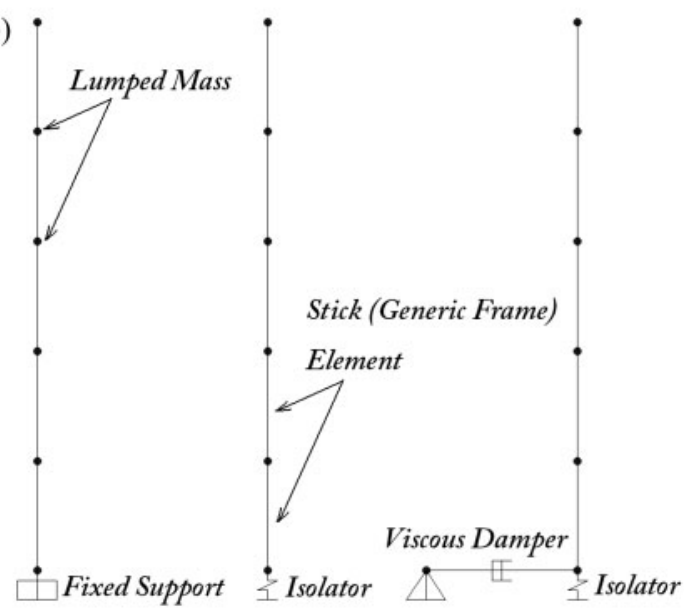

Fig. 1. SAP2000 MDOF model

and can offer only partial description of seismic activity. The Arias Intensity $\left(I_{\mathrm{a}}\right)$, first introduced by Arias (1970), is adopted here as the main descriptor of the ground motion excitations for its ability to capture the earthquake amplitude variation, frequency content and duration. Although the Arias Intensity is a simple index, it serves as a powerful indicator of potential damage in many engineering applications. The Arias Intensity is proportional to the integral over time of the acceleration history squared. It can be computed using the following Eqn. (2):

$$
I_{\mathrm{a}}=\frac{\pi}{2 g} \int_{0}^{t} a(t)^{2} d t
$$

where: $a(t)$ is the ground acceleration history in $g$ 's, and $g$ is the gravitational acceleration. Because the Arias Intensity is a second-order tensor by definition, its trace is an invariant and does not depend on the axis orientation $\left(I_{x}+I_{y}=\right.$ constant). Furthermore, the time domain characterization of the earthquake records is sensitive to directivity effects. Such effects can be particularly significant in near-fault areas 
Table 2. Ground motion records (AlHamaydeh, Hussain 2010)

\begin{tabular}{|c|c|c|c|c|c|}
\hline Shaking level & $\begin{array}{l}\text { Earthquake } \\
\text { label }\end{array}$ & Event name (station) & Magnitude & $\begin{array}{l}\text { PGA/Arias Intensity } \\
(\mathrm{m} / \mathrm{s})\end{array}$ & $\begin{array}{l}\text { Distance to fault } \\
\qquad(\mathrm{km})\end{array}$ \\
\hline \multirow[t]{7}{*}{ 475-years ARP } & EQ1 & 1999 Hector Mine (Hector) & 7.1 & $0.71 / 6.6$ & 10.7 \\
\hline & EQ2 & $\begin{array}{l}1999 \text { Izmit-Kocaeli, Turkey } \\
\text { (Yarimca) }\end{array}$ & 7.4 & $0.77 / 5.3$ & 2.6 \\
\hline & EQ3 & 1999 Duzce, Turkey (Duzce) & 7.1 & $0.69 / 6.6$ & 8.2 \\
\hline & EQ4 & 1989 Loma Prieta (Saratoga) & 7.0 & $0.72 / 5.0$ & 4.1 \\
\hline & EQ5 & 1992 Landers (Yermo) & 7.3 & $0.69 / 7.1$ & 31.0 \\
\hline & EQ6 & 1994 Northridge (Rinaldi) & 6.7 & $0.70 / 4.5$ & 8.6 \\
\hline & EQ7 & 1994 Northridge (Newhall) & 6.7 & $0.66 / 6.8$ & 10.9 \\
\hline \multirow[t]{7}{*}{ 950-years ARP } & EQ8 & 1999 Hector Mine (Hector) & 7.1 & $0.89 / 10.0$ & 10.7 \\
\hline & EQ9 & $\begin{array}{l}1999 \text { Izmit-Kocaeli, Turkey } \\
\text { (Yarimca) }\end{array}$ & 7.4 & $0.99 / 8.4$ & 2.6 \\
\hline & EQ10 & 1999 Duzce, Turkey (Duzce) & 7.1 & $0.83 / 10.1$ & 8.2 \\
\hline & EQ11 & 1989 Loma Prieta (Saratoga) & 7.0 & $0.87 / 7.8$ & 4.1 \\
\hline & EQ12 & 1992 Landers (Lucerne) & 7.3 & $0.84 / 10.7$ & 1.1 \\
\hline & EQ13 & 1994 Northridge (Rinaldi) & 6.7 & $0.87 / 7.1$ & 8.6 \\
\hline & EQ14 & 1994 Northridge (Newhall) & 6.7 & $0.88 / 10.0$ & 10.9 \\
\hline
\end{tabular}

where forward directivity could potentially produce high-velocity pulses.

To represent realistic and practical ground motion records used for design of base-isolated structures, two suites of ground motion records are used from anther publication by the lead author (AlHamaydeh, Hussain 2010). The two ensembles have been prepared for a real seismic-isolated building in Fontana, California, as part of a complete Probabilistic Seismic Hazard Analysis. The ground excitations represent two intensity levels: Maximum Considered Earthquake (MCE) and Design Basis Earthquake (DBE) corresponding to 950 and 475 years Average Return Periods (ARP), respectively. Seven pairs of horizontal ground acceleration records for each level were scaled to match a target design response spectrum in accordance to the (CBC'10) 2010 California Building Code (ICBO 2010). Table 2 summarizes the selected ground motions for both MCE and DBE levels. Figure 2 shows the design response spectra for the 475- and 950-years APR, respectively. Figure 3 shows a sample earthquake after matching it to the design response spectrum.

\section{Results and discussion}

\subsection{Time-history analysis}

The commercial analysis program SAP2000 was used to perform the Time-History Analysis (THA) of the MDOF system subject to all 14 records. The analyses were performed for all three MDOF systems representing the benchmark fixed-base, as well as the isolated buildings with and without dampers. For each of the records, three key response parameters were considered: the $D_{\mathrm{TM}}$, the Peak Damper Force
$\left(P_{\mathrm{DF}}\right)$ and the TSAR at the isolated and the fixed structures.

Tables 3-7 summarize the results for the three response parameters when the 25 different combinations of damping coefficients and damping exponents are investigated under the 14 earthquake records. The total number of considered THA combinations is 350 (5 $c$ values $\times 5 \alpha$ values $\times 14$ records). The response parameters are observed to vary with different trends as the system damping levels are varied. For instance, as the damping is increased, $D_{\mathrm{TM}}$ decreases with a steep slope that gradually plateaus at higher damping levels. On the other hand, the $P_{\mathrm{DF}}$ increases with increasing the damping coefficient and exponent for all the analysis runs. Furthermore, the TSAR decreases with initial introduction of damping and then increases forming concaved-up surfaces. This marks the existence of an optimum practical design solution within the limits of the variables chosen.

The effect of introducing different damping levels ( $c \& \alpha$ values) on the considered response parameters $\left(D_{\mathrm{TM}}, P_{\mathrm{DF}} \& \mathrm{TSAR}\right)$ is illustrated in Figures $4-6$. It should be noted that increasing the damping coefficient and exponent results in raising the top floor acceleration under the different excitation ground records.

\subsection{Multiple regression analysis}

The basic idea of regression is to relate a dependent variable $\boldsymbol{Y}$ to a vector of independent variables $\boldsymbol{X}=\left[\boldsymbol{x}_{1}\right.$, $\left.\boldsymbol{x}_{2}, \ldots, \boldsymbol{x}_{\boldsymbol{k}}\right]^{\boldsymbol{T}}$. Linear regression is characterized by the fact that the prediction equation depends linearly on one or more unknown parameters. On the other hand, nonlinear regression is often used to develop empirical models with arbitrary relationships (usually 

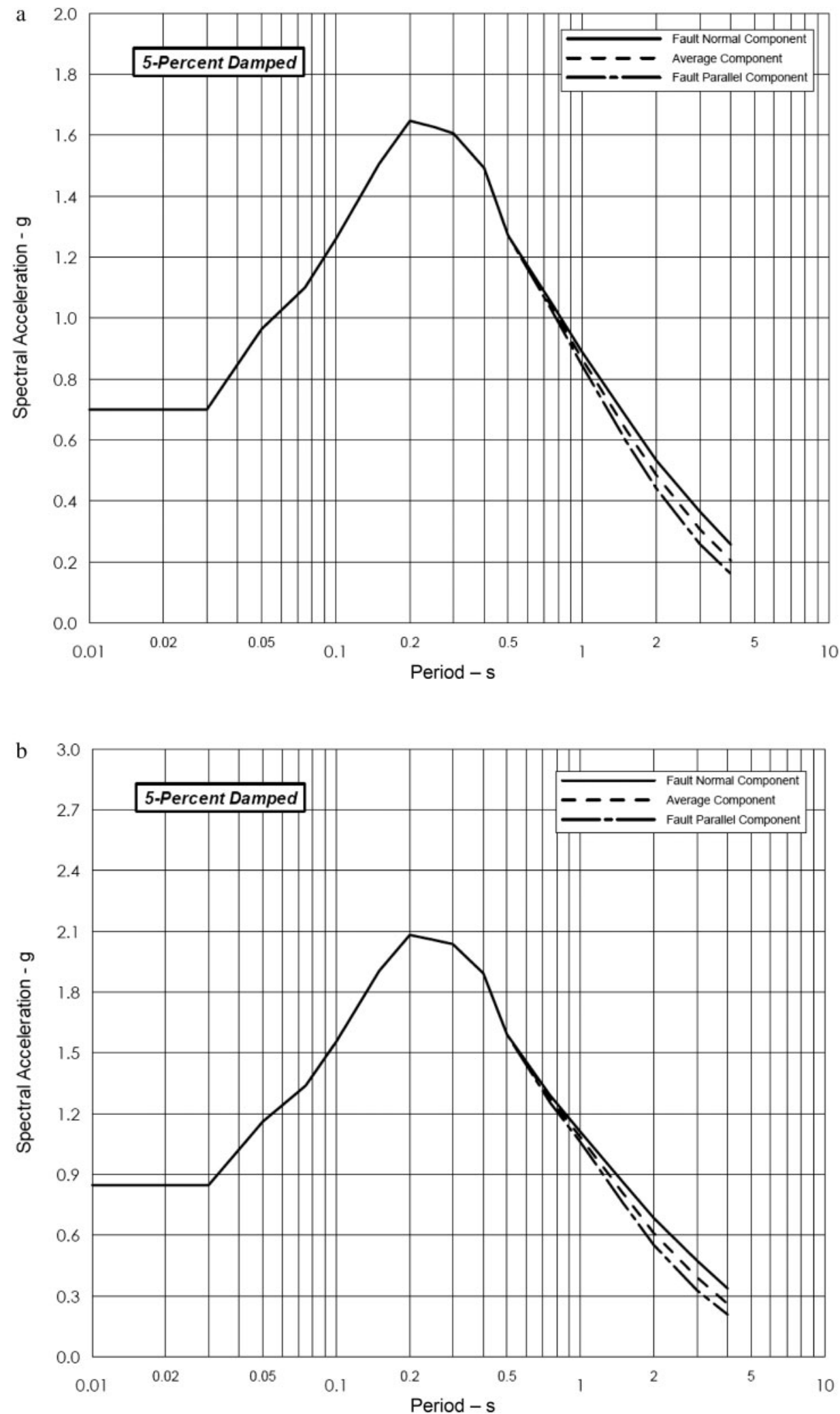

Fig. 2. Design response spectra for DBE and MCE levels (AlHamaydeh, Hussain 2010)

nonlinear) between independent and dependent variables. This is typically accomplished via iterative estimation algorithms. Often times, one can adopt linear least squares to achieve this. The nonlinear regression method involves creating new variables from the original data, such that they are nonlinear functions of the original variables. If the new variables are constructed properly, the nonlinear function of the original variables can be expressed as a linear function of the new variables. Inspection of graphical 

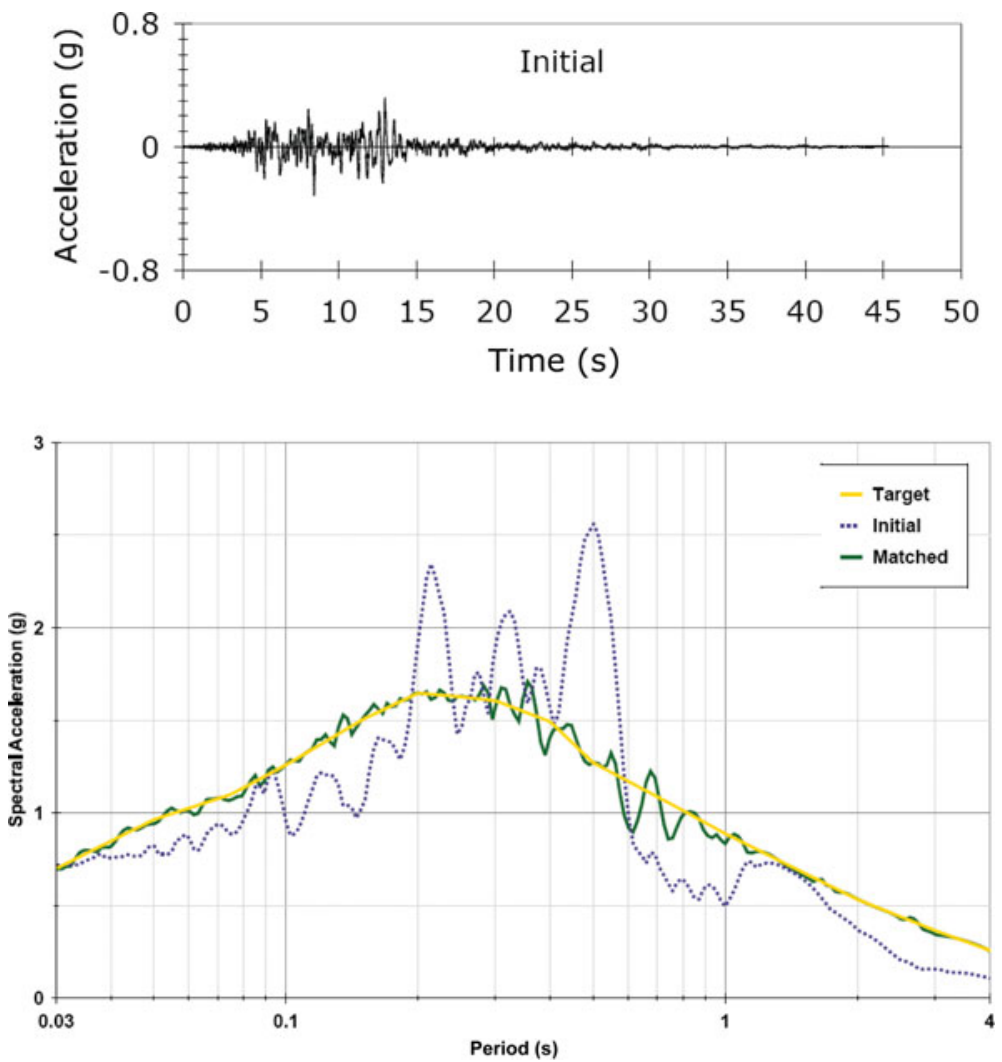

Fig. 3. Sample of a response spectrum-matched time history record (AlHamaydeh, Hussain 2010)

representations of the variables pairs through scatter diagrams can provide an overview of the inherent relationships (direct, inverse, linear, nonlinear, etc.). If curvature in the relationships is evident, transforming the variables and/or explicitly allowing for nonlinear components could be utilized (El-Shaarawi, Walter 2002).

\subsubsection{Mathematical modeling based on MRA}

The dynamic behavior of the SI system is complex and can be sensitive to several parameters. Therefore, more simplified models that predict the response parameter of the SI system with reasonable accuracy are sought. The theoretical results based on SAP2000 program

Table 3. Response parameters when $C=175 \mathrm{kN}-\mathrm{s} / \mathrm{m}$

\begin{tabular}{|c|c|c|c|c|c|c|c|c|c|c|c|c|c|c|c|c|c|c|}
\hline \multirow[b]{3}{*}{ Earthquake } & \multicolumn{6}{|c|}{$P_{\mathrm{DF}}(\mathrm{kN})$} & \multicolumn{6}{|c|}{$D_{\mathrm{TM}}(\mathrm{m})$} & \multicolumn{6}{|c|}{ TSAR } \\
\hline & \multicolumn{6}{|c|}{$\alpha$} & \multicolumn{6}{|c|}{$\alpha$} & \multicolumn{6}{|c|}{$\alpha$} \\
\hline & ND & 0.4 & 0.55 & 0.7 & 0.85 & 1 & ND & 0.4 & 0.55 & 0.7 & 0.85 & 1 & ND & 0.4 & 0.55 & 0.7 & 0.85 & 1 \\
\hline EQ1 & & 19.6 & 31.1 & 44.9 & 61.3 & 83.6 & 0.70 & 0.49 & 0.40 & 0.29 & 0.20 & 0.14 & 0.186 & 0.156 & 0.144 & 0.138 & 0.157 & 0.180 \\
\hline EQ2 & & 22.2 & 36.5 & 53.4 & 71.6 & 88.5 & 0.92 & 0.57 & 0.45 & 0.33 & 0.24 & 0.19 & 0.237 & 0.170 & 0.146 & 0.124 & 0.127 & 0.184 \\
\hline EQ3 & & 20.0 & 33.4 & 50.7 & 70.4 & 89.9 & 0.69 & 0.48 & 0.40 & 0.30 & 0.20 & 0.17 & 0.175 & 0.139 & 0.127 & 0.115 & 0.127 & 0.175 \\
\hline EQ4 & & 22.2 & 36.5 & 58.7 & 89.0 & 124.1 & 0.72 & 0.50 & 0.43 & 0.35 & 0.27 & 0.20 & 0.185 & 0.156 & 0.145 & 0.138 & 0.174 & 0.217 \\
\hline EQ5 & & 21.4 & 35.1 & 54.7 & 79.3 & 105.9 & 0.74 & 0.47 & 0.38 & 0.30 & 0.23 & 0.17 & 0.192 & 0.144 & 0.134 & 0.138 & 0.148 & 0.173 \\
\hline EQ6 & & 21.4 & 36.0 & 56.0 & 82.5 & 109.0 & 0.73 & 0.47 & 0.41 & 0.35 & 0.28 & 0.22 & 0.188 & 0.149 & 0.149 & 0.162 & 0.185 & 0.215 \\
\hline EQ7 & & 22.7 & 38.7 & 58.7 & 78.6 & 110.3 & 0.83 & 0.47 & 0.42 & 0.35 & 0.27 & 0.20 & 0.213 & 0.144 & 0.135 & 0.137 & 0.163 & 0.200 \\
\hline EQ8 & & 21.4 & 35.1 & 52.5 & 75.5 & 102.3 & 1.03 & 0.79 & 0.65 & 0.49 & 0.34 & 0.24 & 0.269 & 0.232 & 0.214 & 0.196 & 0.219 & 0.248 \\
\hline EQ9 & & 25.4 & 43.1 & 65.4 & 96.8 & 139.7 & 0.87 & 0.57 & 0.45 & 0.33 & 0.26 & 0.19 & 0.224 & 0.164 & 0.143 & 0.159 & 0.193 & 0.267 \\
\hline EQ10 & & 22.7 & 37.8 & 59.2 & 83.1 & 111.2 & 0.87 & 0.64 & 0.53 & 0.40 & 0.28 & 0.20 & 0.223 & 0.182 & 0.163 & 0.148 & 0.157 & 0.219 \\
\hline EQ11 & & 24.9 & 43.1 & 69.8 & 109.3 & 158.8 & 0.90 & 0.67 & 0.58 & 0.47 & 0.35 & 0.25 & 0.233 & 0.200 & 0.186 & 0.173 & 0.215 & 0.273 \\
\hline EQ12 & & 24.0 & 40.9 & 62.7 & 98.0 & 137.5 & 1.09 & 0.83 & 0.66 & 0.51 & 0.41 & 0.30 & 0.283 & 0.236 & 0.212 & 0.207 & 0.228 & 0.275 \\
\hline EQ13 & & 24.0 & 42.3 & 67.6 & 100.8 & 134.8 & 0.89 & 0.65 & 0.57 & 0.48 & 0.38 & 0.29 & 0.230 & 0.193 & 0.195 & 0.208 & 0.235 & 0.272 \\
\hline EQ14 & & 24.9 & 43.1 & 68.1 & 94.4 & 134.3 & 1.05 & 0.64 & 0.57 & 0.47 & 0.36 & 0.26 & 0.271 & 0.199 & 0.192 & 0.178 & 0.206 & 0.255 \\
\hline
\end{tabular}


Table 4. Response parameters when $C=263 \mathrm{kN}-\mathrm{s} / \mathrm{m}$

\begin{tabular}{|c|c|c|c|c|c|c|c|c|c|c|c|c|c|c|c|c|c|c|}
\hline \multirow[b]{3}{*}{ Earthquake } & \multicolumn{6}{|c|}{$P_{\mathrm{DF}}(\mathrm{kN})$} & \multicolumn{6}{|c|}{$D_{\mathrm{TM}}(\mathrm{m})$} & \multicolumn{6}{|c|}{ TSAR } \\
\hline & \multicolumn{6}{|c|}{$\alpha$} & \multicolumn{6}{|c|}{$\alpha$} & \multicolumn{6}{|c|}{$\alpha$} \\
\hline & ND & 0.4 & 0.55 & 0.7 & 0.85 & 1 & ND & 0.4 & 0.55 & 0.7 & 0.85 & 1 & ND & 0.4 & 0.55 & 0.7 & 0.85 & 1 \\
\hline EQ1 & & 28.0 & 41.8 & 58.7 & 81.3 & 106.3 & 0.70 & 0.41 & 0.30 & 0.20 & 0.14 & 0.10 & 0.186 & 0.146 & 0.133 & 0.149 & 0.175 & 0.224 \\
\hline EQ2 & & 31.1 & 47.6 & 66.3 & 84.1 & 97.9 & 0.92 & 0.45 & 0.32 & 0.23 & 0.18 & 0.14 & 0.237 & 0.149 & 0.133 & 0.154 & 0.186 & 0.246 \\
\hline EQ3 & & 28.9 & 45.4 & 64.9 & 85.1 & 113.4 & 0.69 & 0.40 & 0.30 & 0.20 & 0.16 & 0.13 & 0.175 & 0.131 & 0.125 & 0.131 & 0.164 & 0.218 \\
\hline EQ4 & & 31.1 & 50.7 & 79.6 & 114.9 & 152.6 & 0.72 & 0.44 & 0.36 & 0.28 & 0.20 & 0.14 & 0.185 & 0.157 & 0.144 & 0.164 & 0.209 & 0.268 \\
\hline EQ5 & & 30.2 & 48.5 & 72.1 & 99.0 & 124.6 & 0.74 & 0.40 & 0.32 & 0.24 & 0.17 & 0.13 & 0.192 & 0.141 & 0.134 & 0.151 & 0.182 & 0.210 \\
\hline EQ6 & & 30.7 & 49.4 & 74.7 & 101.5 & 125.0 & 0.73 & 0.41 & 0.35 & 0.28 & 0.22 & 0.17 & 0.188 & 0.149 & 0.154 & 0.177 & 0.209 & 0.243 \\
\hline EQ7 & & 32.5 & 51.6 & 72.1 & 102.2 & 137.5 & 0.83 & 0.42 & 0.35 & 0.27 & 0.20 & 0.14 & 0.213 & 0.136 & 0.136 & 0.153 & 0.188 & 0.235 \\
\hline EQ8 & & 30.7 & 47.6 & 69.8 & 97.1 & 132.6 & 1.03 & 0.69 & 0.52 & 0.35 & 0.23 & 0.16 & 0.269 & 0.217 & 0.198 & 0.208 & 0.239 & 0.276 \\
\hline EQ9 & & 35.6 & 56.5 & 85.9 & 128.1 & 169.0 & 0.87 & 0.47 & 0.35 & 0.27 & 0.20 & 0.15 & 0.224 & 0.154 & 0.151 & 0.183 & 0.247 & 0.335 \\
\hline EQ10 & & 32.0 & 51.6 & 75.6 & 104.4 & 143.2 & 0.87 & 0.55 & 0.42 & 0.28 & 0.19 & 0.15 & 0.223 & 0.169 & 0.149 & 0.156 & 0.201 & 0.271 \\
\hline EQ11 & & 35.6 & 58.7 & 95.2 & 142.8 & 195.3 & 0.90 & 0.59 & 0.48 & 0.37 & 0.27 & 0.18 & 0.233 & 0.197 & 0.179 & 0.196 & 0.257 & 0.328 \\
\hline EQ12 & & 34.3 & 55.2 & 88.1 & 128.4 & 164.1 & 1.09 & 0.71 & 0.53 & 0.43 & 0.32 & 0.23 & 0.283 & 0.218 & 0.206 & 0.224 & 0.255 & 0.311 \\
\hline EQ13 & & 34.7 & 57.8 & 89.0 & 124.5 & 157.0 & 0.89 & 0.58 & 0.49 & 0.39 & 0.29 & 0.22 & 0.230 & 0.187 & 0.196 & 0.220 & 0.258 & 0.305 \\
\hline EQ14 & & 35.6 & 58.7 & 84.1 & 122.4 & 164.1 & 1.05 & 0.58 & 0.48 & 0.37 & 0.27 & 0.19 & 0.271 & 0.199 & 0.180 & 0.192 & 0.237 & 0.290 \\
\hline
\end{tabular}

shown in Tables 4-7 are re-arranged to fit the MRA. Three dependent output variables ( $\left.P_{\mathrm{DF}}, D_{\mathrm{TM}}, \mathrm{TSAR}\right)$ and four independent input variables $\left(C, \alpha\right.$, PGA, $\left.I_{\mathrm{a}}\right)$ are considered in the modeling phase. Then, several models for each key response parameter are established by incorporating the data set into MRA. The THA data set is further divided into two subsets: Set 1 , consisting of THA results from 300 (c, $\alpha, \mathrm{EQ})$ combinations is used to produce mathematical models via MRA; Set 2, consisting of THA results from 50 (c, $\alpha, \mathrm{EQ})$ combinations is used to test the developed mathematical models. It should be emphasized here that the data from 50 testing combinations were not included in the modeling phase.

Several trials were made using the SPSS statistics computer package (SPSS 2010) to select the best-fit formula. The details of these trials are discussed in the following sections.

\subsubsection{Scatter plots}

To acquire an overall perspective of the inherent relationships of the problem, the pairs of the variables of interest are examined in the matrix scatter diagram shown in Figure 7. In an effort to capture the simplest form of relationships via regression, linear relationships are investigated first in the MRA. Subsequently, nonlinear components are explicitly allowed in the formulation.

\subsubsection{Linear regression models}

In a simple regression model, the constant represents the $Y$-intercept of the regression line (Fig. 8).

Table 5. Response parameters when $C=350 \mathrm{kN}-\mathrm{s} / \mathrm{m}$

\begin{tabular}{|c|c|c|c|c|c|c|c|c|c|c|c|c|c|c|c|c|c|c|}
\hline \multirow[b]{3}{*}{ Earthquake } & \multicolumn{6}{|c|}{$P_{\mathrm{DF}}(\mathrm{kN})$} & \multicolumn{6}{|c|}{$D_{\mathrm{TM}}(\mathrm{m})$} & \multicolumn{6}{|c|}{ TSAR } \\
\hline & \multicolumn{6}{|c|}{$\alpha$} & \multicolumn{6}{|c|}{$\alpha$} & \multicolumn{6}{|c|}{$\alpha$} \\
\hline & ND & 0.4 & 0.55 & 0.7 & 0.85 & 1 & ND & 0.4 & 0.55 & 0.7 & 0.85 & 1 & ND & 0.4 & 0.55 & 0.7 & 0.85 & 1 \\
\hline EQ1 & & 35.1 & 50.7 & 72.5 & 97.9 & 124.1 & 0.70 & 0.34 & 0.22 & 0.14 & 0.10 & 0.08 & 0.186 & 0.135 & 0.136 & 0.164 & 0.205 & 0.256 \\
\hline EQ2 & & 38.7 & 56.9 & 76.1 & 92.0 & 103.6 & 0.92 & 0.36 & 0.24 & 0.19 & 0.15 & 0.12 & 0.237 & 0.154 & 0.172 & 0.203 & 0.242 & 0.305 \\
\hline EQ3 & & 36.9 & 55.6 & 76.1 & 102.5 & 131.7 & 0.69 & 0.33 & 0.23 & 0.16 & 0.13 & 0.11 & 0.175 & 0.148 & 0.147 & 0.148 & 0.195 & 0.253 \\
\hline EQ4 & & 39.6 & 64.9 & 97.9 & 135.3 & 172.1 & 0.72 & 0.39 & 0.31 & 0.23 & 0.16 & 0.11 & 0.185 & 0.154 & 0.152 & 0.193 & 0.241 & 0.314 \\
\hline EQ5 & & 38.3 & 60.1 & 86.3 & 113.2 & 134.8 & 0.74 & 0.35 & 0.27 & 0.19 & 0.14 & 0.11 & 0.192 & 0.135 & 0.149 & 0.182 & 0.210 & 0.238 \\
\hline EQ6 & & 39.1 & 61.4 & 89.0 & 114.3 & 145.0 & 0.73 & 0.36 & 0.29 & 0.23 & 0.18 & 0.13 & 0.188 & 0.152 & 0.164 & 0.196 & 0.235 & 0.268 \\
\hline EQ7 & & 40.9 & 61.4 & 87.2 & 121.5 & 157.0 & 0.83 & 0.37 & 0.29 & 0.22 & 0.16 & 0.11 & 0.213 & 0.136 & 0.138 & 0.169 & 0.225 & 0.270 \\
\hline EQ8 & & 38.7 & 58.7 & 85.0 & 118.7 & 156.1 & 1.03 & 0.59 & 0.41 & 0.26 & 0.17 & 0.12 & 0.269 & 0.204 & 0.192 & 0.221 & 0.260 & 0.324 \\
\hline EQ9 & & 44.5 & 68.1 & 107.2 & 150.4 & 185.9 & 0.87 & 0.38 & 0.31 & 0.23 & 0.16 & 0.12 & 0.224 & 0.152 & 0.168 & 0.213 & 0.298 & 0.383 \\
\hline EQ10 & & 40.9 & 63.6 & 89.0 & 127.2 & 167.7 & 0.87 & 0.47 & 0.33 & 0.20 & 0.16 & 0.13 & 0.223 & 0.165 & 0.172 & 0.177 & 0.241 & 0.320 \\
\hline EQ11 & & 44.9 & 74.7 & 117.4 & 168.9 & 219.7 & 0.90 & 0.52 & 0.41 & 0.30 & 0.21 & 0.14 & 0.233 & 0.208 & 0.181 & 0.231 & 0.290 & 0.384 \\
\hline EQ12 & & 44.0 & 70.3 & 109.0 & 149.6 & 187.7 & 1.09 & 0.60 & 0.47 & 0.36 & 0.26 & 0.18 & 0.283 & 0.207 & 0.213 & 0.236 & 0.287 & 0.326 \\
\hline EQ13 & & 44.5 & 70.7 & 106.8 & 139.3 & 185.5 & 0.89 & 0.52 & 0.42 & 0.32 & 0.24 & 0.18 & 0.230 & 0.184 & 0.201 & 0.234 & 0.283 & 0.335 \\
\hline EQ14 & & 44.9 & 70.7 & 102.8 & 144.3 & 186.4 & 1.05 & 0.52 & 0.41 & 0.30 & 0.21 & 0.15 & 0.271 & 0.187 & 0.178 & 0.213 & 0.262 & 0.332 \\
\hline
\end{tabular}


Table 6. Response parameters when $C=438 \mathrm{kN}-\mathrm{s} / \mathrm{m}$

\begin{tabular}{|c|c|c|c|c|c|c|c|c|c|c|c|c|c|c|c|c|c|c|}
\hline \multirow[b]{3}{*}{ Earthquake } & \multicolumn{6}{|c|}{$P_{\mathrm{DF}}(\mathrm{kN})$} & \multicolumn{6}{|c|}{$D_{\mathrm{TM}}(\mathrm{m})$} & \multicolumn{6}{|c|}{ TSAR } \\
\hline & \multicolumn{6}{|c|}{$\alpha$} & \multicolumn{6}{|c|}{$\alpha$} & \multicolumn{6}{|c|}{$\alpha$} \\
\hline & ND & 0.4 & 0.55 & 0.7 & 0.85 & 1 & ND & 0.4 & 0.55 & 0.7 & 0.85 & 1 & ND & 0.4 & 0.55 & 0.7 & 0.85 & 1 \\
\hline EQ1 & & 41.8 & 60.5 & 85.0 & 111.9 & 137.5 & 0.70 & 0.27 & 0.17 & 0.11 & 0.08 & 0.06 & 0.186 & 0.129 & 0.151 & 0.201 & 0.237 & 0.280 \\
\hline EQ2 & & 45.4 & 64.9 & 83.2 & 97.0 & 120.5 & 0.92 & 0.28 & 0.20 & 0.15 & 0.12 & 0.10 & 0.237 & 0.182 & 0.212 & 0.249 & 0.292 & 0.355 \\
\hline EQ3 & & 44.0 & 64.1 & 87.2 & 117.3 & 146.3 & 0.69 & 0.27 & 0.17 & 0.13 & 0.11 & 0.09 & 0.175 & 0.163 & 0.160 & 0.179 & 0.229 & 0.289 \\
\hline EQ4 & & 48.5 & 77.4 & 113.4 & 151.7 & 185.5 & 0.72 & 0.35 & 0.27 & 0.19 & 0.13 & 0.09 & 0.185 & 0.177 & 0.174 & 0.217 & 0.280 & 0.350 \\
\hline EQ5 & & 46.3 & 70.3 & 97.4 & 123.2 & 143.2 & 0.74 & 0.31 & 0.23 & 0.16 & 0.12 & 0.09 & 0.192 & 0.161 & 0.177 & 0.207 & 0.234 & 0.265 \\
\hline EQ6 & & 47.2 & 72.1 & 99.6 & 127.6 & 166.4 & 0.73 & 0.32 & 0.25 & 0.19 & 0.15 & 0.11 & 0.188 & 0.167 & 0.179 & 0.220 & 0.261 & 0.289 \\
\hline EQ7 & & 48.0 & 69.4 & 101.0 & 137.5 & 171.7 & 0.83 & 0.32 & 0.25 & 0.18 & 0.13 & 0.09 & 0.213 & 0.134 & 0.166 & 0.206 & 0.254 & 0.316 \\
\hline EQ8 & & 46.7 & 69.4 & 100.1 & 137.4 & 174.4 & 1.03 & 0.50 & 0.32 & 0.20 & 0.14 & 0.10 & 0.269 & 0.196 & 0.199 & 0.236 & 0.303 & 0.367 \\
\hline EQ9 & & 52.0 & 82.7 & 125.0 & 166.2 & 196.2 & 0.87 & 0.36 & 0.28 & 0.20 & 0.14 & 0.10 & 0.224 & 0.159 & 0.191 & 0.253 & 0.341 & 0.420 \\
\hline EQ10 & & 48.9 & 73.0 & 105.4 & 146.6 & 187.3 & 0.87 & 0.40 & 0.25 & 0.17 & 0.14 & 0.11 & 0.223 & 0.180 & 0.189 & 0.215 & 0.285 & 0.368 \\
\hline EQ11 & & 53.8 & 89.4 & 136.6 & 189.4 & 238.0 & 0.90 & 0.47 & 0.36 & 0.26 & 0.17 & 0.11 & 0.233 & 0.192 & 0.198 & 0.260 & 0.334 & 0.428 \\
\hline EQ12 & & 52.0 & 85.0 & 126.8 & 164.1 & 218.0 & 1.09 & 0.53 & 0.42 & 0.31 & 0.21 & 0.15 & 0.283 & 0.211 & 0.229 & 0.261 & 0.309 & 0.366 \\
\hline EQ13 & & 53.4 & 84.1 & 120.5 & 158.0 & 214.4 & 0.89 & 0.47 & 0.37 & 0.27 & 0.20 & 0.14 & 0.230 & 0.187 & 0.209 & 0.252 & 0.310 & 0.360 \\
\hline EQ14 & & 53.8 & 80.1 & 118.8 & 162.0 & 203.3 & 1.05 & 0.47 & 0.36 & 0.25 & 0.17 & 0.12 & 0.271 & 0.182 & 0.202 & 0.251 & 0.312 & 0.385 \\
\hline
\end{tabular}

On the other hand, in a multiple regression model, the constant represents the value that would be predicted for the dependent variable if all the independent variables were simultaneously equal to zero. Different linear regression models among the three dependent variables $\left(P_{\mathrm{DF}}, D_{\mathrm{TM}}, \mathrm{TSAR}\right)$ and the four independent variables $\left(C, \alpha\right.$, PGA, $\left.I_{\mathrm{a}}\right)$ are examined using Set 1 data. Table 8 summarizes the SPSS outputs for the $\left(P_{\mathrm{DF}}, D_{\mathrm{TM}}, \mathrm{TSAR}\right)$ models. This includes the various terms used to explain the overall model fit in the regression analysis, such as:

- $R^{2}$ : The proportion of variance in the dependent variable $\left(P_{\mathrm{DF}}, D_{\mathrm{TM}}\right.$, TSAR) which can be explained by the independent variables $(C, \alpha$, PGA, $I_{\mathrm{a}}$ ) (Fig. 8). This is an overall measure of the strength of association and does not reflect the extent to which any particular independent variable is associated with the dependent variable. Adjusted $R^{2}$ is an adjustment of the $R^{2}$ that penalizes the addition of extraneous predictors to the model. Adjusted $R^{2}=1-\left(\left(1-R^{2}\right)((N-1) /(N-k-\right.$ $1)$ ), where $k$ is the number of predictors and $N$ is the number of data points;

- Model $F$-value and $F$-significance: The $F$-statistic the $p$-value associated with it. The $F$ statistic is the Mean Square (Regression) divided by the Mean Square (Residual). The $p$ value is compared to some alpha level in testing the null hypothesis that all of the model coefficients are zeros;

Table 7. Response parameters when $C=525 \mathrm{kN}-\mathrm{s} / \mathrm{m}$

\begin{tabular}{|c|c|c|c|c|c|c|c|c|c|c|c|c|c|c|c|c|c|c|}
\hline \multirow[b]{3}{*}{ Earthquake } & \multicolumn{6}{|c|}{$P_{\mathrm{DF}}(\mathrm{kN})$} & \multicolumn{6}{|c|}{$D_{\mathrm{TM}}(\mathrm{m})$} & \multicolumn{6}{|c|}{ TSAR } \\
\hline & \multicolumn{6}{|c|}{$\alpha$} & \multicolumn{6}{|c|}{$\alpha$} & \multicolumn{6}{|c|}{$\alpha$} \\
\hline & ND & 0.4 & 0.55 & 0.7 & 0.85 & 1 & ND & 0.4 & 0.55 & 0.7 & 0.85 & 1 & ND & 0.4 & 0.55 & 0.7 & 0.85 & 1 \\
\hline EQ1 & & 47.6 & 69.8 & 96.5 & 123.5 & 147.2 & 0.70 & 0.22 & 0.14 & 0.09 & 0.07 & 0.05 & 0.186 & 0.152 & 0.183 & 0.231 & 0.263 & 0.299 \\
\hline EQ2 & & 51.6 & 71.6 & 89.0 & 103.8 & 140.1 & 0.92 & 0.22 & 0.17 & 0.13 & 0.11 & 0.09 & 0.237 & 0.214 & 0.249 & 0.290 & 0.337 & 0.397 \\
\hline EQ3 & & 50.7 & 71.2 & 98.8 & 129.6 & 157.5 & 0.69 & 0.22 & 0.14 & 0.12 & 0.09 & 0.08 & 0.175 & 0.177 & 0.168 & 0.208 & 0.259 & 0.320 \\
\hline EQ4 & & 56.9 & 89.0 & 126.3 & 164.4 & 194.4 & 0.72 & 0.32 & 0.24 & 0.17 & 0.11 & 0.08 & 0.185 & 0.163 & 0.196 & 0.243 & 0.313 & 0.380 \\
\hline EQ5 & & 53.8 & 79.2 & 107.2 & 130.3 & 155.7 & 0.74 & 0.28 & 0.20 & 0.13 & 0.10 & 0.08 & 0.192 & 0.179 & 0.205 & 0.234 & 0.259 & 0.285 \\
\hline EQ6 & & 54.3 & 81.8 & 108.5 & 144.1 & 185.5 & 0.73 & 0.29 & 0.22 & 0.17 & 0.13 & 0.10 & 0.188 & 0.186 & 0.200 & 0.247 & 0.284 & 0.306 \\
\hline EQ7 & & 54.7 & 79.2 & 113.9 & 150.8 & 184.2 & 0.83 & 0.29 & 0.21 & 0.15 & 0.11 & 0.08 & 0.213 & 0.154 & 0.193 & 0.239 & 0.293 & 0.354 \\
\hline EQ8 & & 53.4 & 79.2 & 114.8 & 154.4 & 192.2 & 1.03 & 0.43 & 0.26 & 0.16 & 0.11 & 0.08 & 0.269 & 0.190 & 0.208 & 0.270 & 0.342 & 0.405 \\
\hline EQ9 & & 59.2 & 96.1 & 139.7 & 177.8 & 202.4 & 0.87 & 0.33 & 0.25 & 0.17 & 0.12 & 0.08 & 0.224 & 0.180 & 0.221 & 0.290 & 0.378 & 0.450 \\
\hline EQ10 & & 56.5 & 81.8 & 120.5 & 163.0 & 202.4 & 0.87 & 0.33 & 0.20 & 0.15 & 0.12 & 0.09 & 0.223 & 0.207 & 0.201 & 0.250 & 0.324 & 0.408 \\
\hline EQ11 & & 63.2 & 103.6 & 153.0 & 205.7 & 251.3 & 0.90 & 0.43 & 0.32 & 0.22 & 0.15 & 0.10 & 0.233 & 0.199 & 0.226 & 0.284 & 0.374 & 0.464 \\
\hline EQ12 & & 60.9 & 97.9 & 141.0 & 181.6 & 244.2 & 1.09 & 0.50 & 0.38 & 0.27 & 0.18 & 0.12 & 0.283 & 0.228 & 0.257 & 0.289 & 0.324 & 0.422 \\
\hline EQ13 & & 61.4 & 95.2 & 130.8 & 178.9 & 238.9 & 0.89 & 0.42 & 0.33 & 0.24 & 0.17 & 0.12 & 0.230 & 0.204 & 0.218 & 0.273 & 0.339 & 0.382 \\
\hline EQ14 & & 61.4 & 91.6 & 133.0 & 177.2 & 228.2 & 1.05 & 0.42 & 0.31 & 0.21 & 0.15 & 0.10 & 0.271 & 0.198 & 0.242 & 0.288 & 0.361 & 0.429 \\
\hline
\end{tabular}



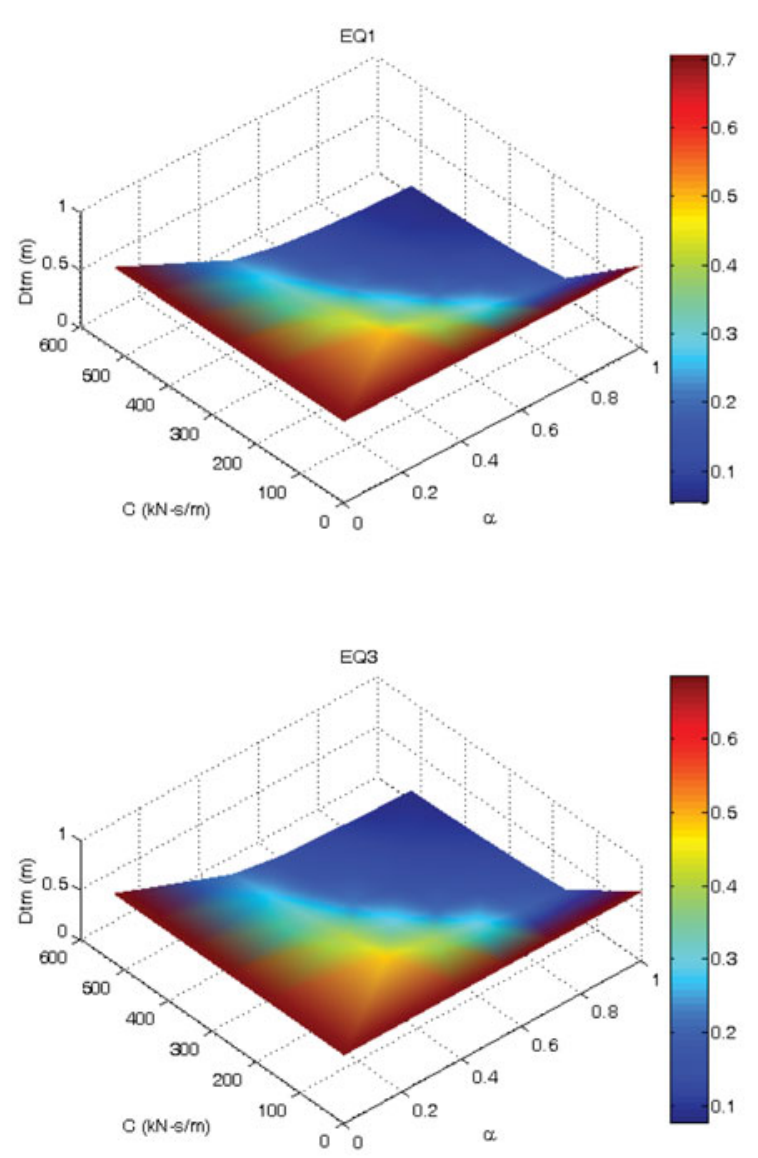

Fig. 4. Total maximum displacement $\left(D_{\mathrm{TM}}\right)$

- Coefficient $t$-value and $t$-significance: the $t$ statistics and their associated 2-tailed $p$-values used in testing whether a given coefficient is significantly different from zero using an alpha of 0.05 .

The results of the best three models are summarized in Table 8 . The three multiple regression models do not include constant terms. Consequently, if all the independent variables take the value of zero simultaneously, the dependent variables will also be equal to zero. This is in agreement with the modeled physical phenomenon.

Despite the apparent best-fitting (high values of $R^{2}$, as well as passing the $F$ - and $t$-tests), all three linear models are deemed physically unsound for the SI systems. This is attributed to the negative signs on at least one of the independent variables coefficients. For example, this implies that increasing the PGA decreases the $D_{\mathrm{TM}}$, which is generally, but not necessarily, counter intuitive. Consequently, nonlinear regression models are reverted to.

\subsubsection{Nonlinear regression models}

Nonlinear regression is appropriate, when the relationship between the dependent and independent variables is not intrinsically linear. Nonlinear regression
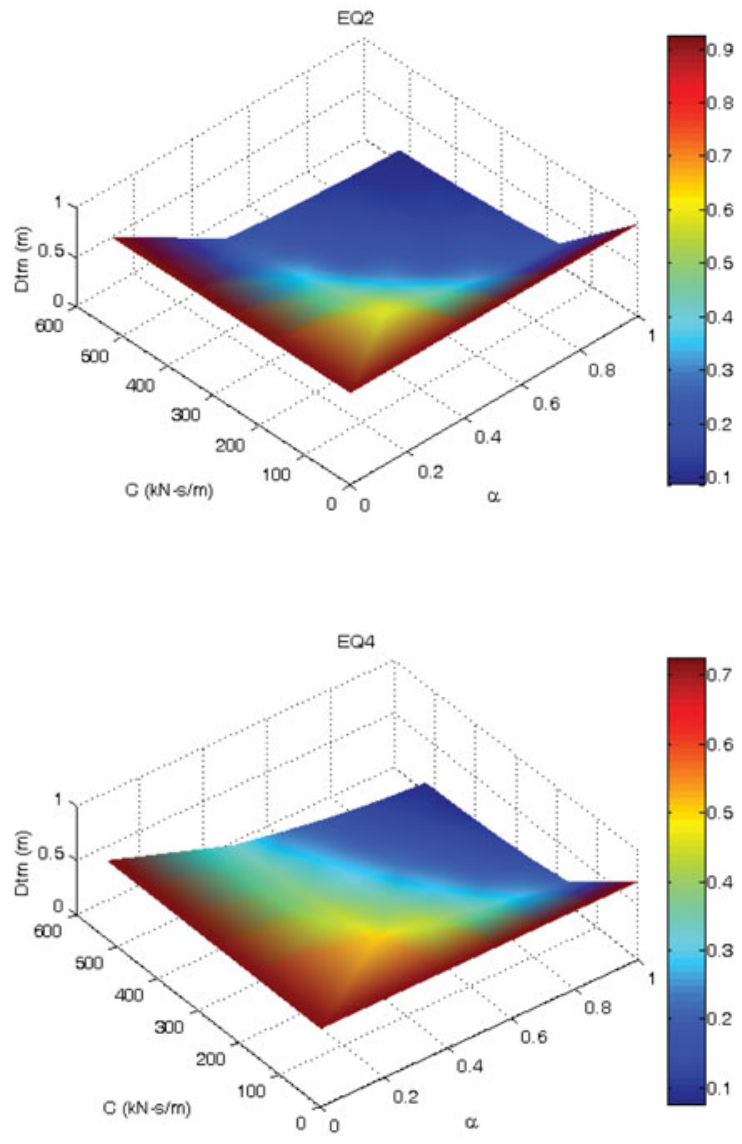

can estimate models with arbitrary relationships between independent and dependent variables. The relationships of the dependent variables $\left(P_{\mathrm{DF}}, D_{\mathrm{TM}}\right.$ and TSRA) in terms of four independent variables $(C$, $\alpha$, PGA, $I_{\mathrm{a}}$ ) are generally non-flat. When nonlinear regression is utilized to develop relationship models, iterative estimation algorithms are used to quantify the parameters that define such models. These parameters can be additive constants, multiplicative coefficients, exponents, or any other values used in evaluating functions. All parameters that are defined must be assigned appropriate initial values, preferably as close as possible to the expected final solution. Poor initial guesses can result in failure to converge or in convergence on a local solution or a physically impossible one. Furthermore, some models require certain constraints to force convergence when the need arises. To avoid this dilemma, new nonlinear functions are created from the original variables in the original data set. These new variables are created in forms that guarantee that the curved functions of the original variables are transformed to linear functions of the new variables. This is described by Eqns $(3 a, 3 b)$ :

$$
\begin{gathered}
Y=a_{1} f_{i} ; \\
f_{i}=g_{i}\left(C, P G A, I_{a}, \alpha\right),
\end{gathered}
$$



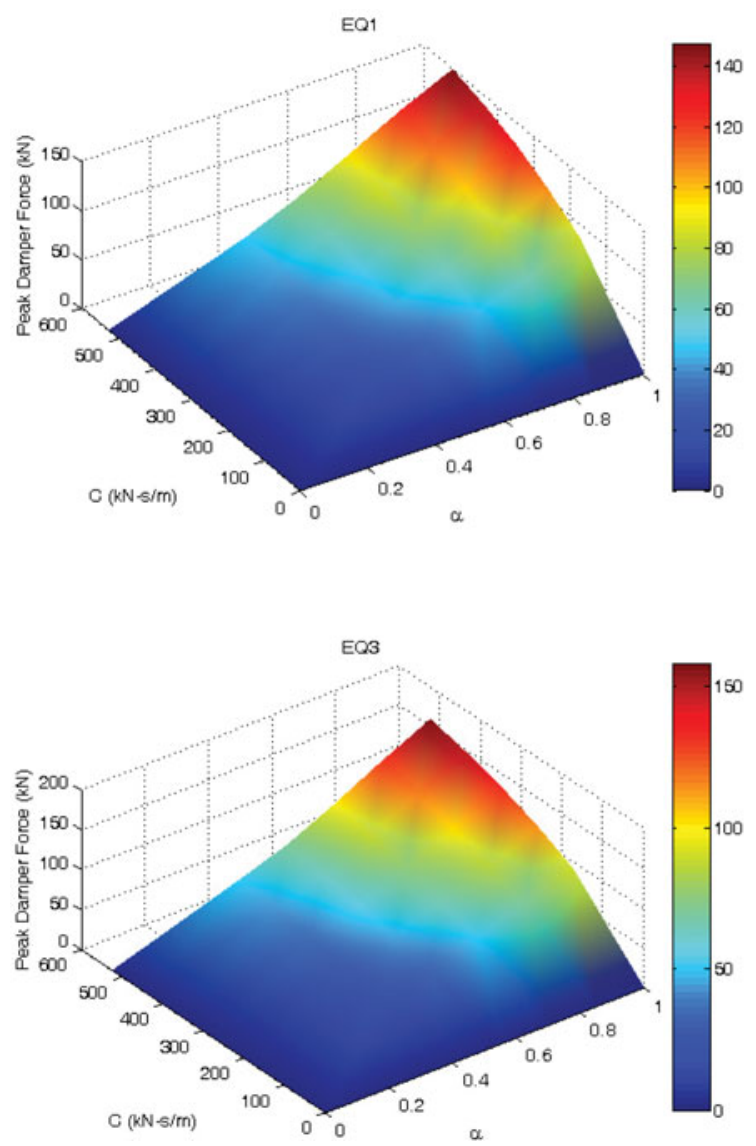

Fig. 5. Peak damper force $\left(P_{\mathrm{DF}}\right)$

where $Y$ represents the dependent variables $P_{\mathrm{DF}}, D_{\mathrm{TM}}$, or TSAR.

A careful selection of the function $f_{i}$ in Eqn. (3b) results in a linear relationship in Eqn. (3a), in which the constant $a_{1}$ can be estimated using traditional linear regression procedures. To find the transformation functions, $g_{i}$, different nonlinear models are considered. Based on several trials of functions that preserve the physical interpretation, many transformation functions were obtained. The best identified transformation functions are as follows:

$$
f_{i}=C^{a_{2}} \times P G A^{\left(a_{3} \alpha\right)} I_{a}^{\left(a_{4} \alpha\right)},
$$

where the exponents $a_{2}, a_{3}$ and $a_{4}$ may take values in the range of -1.0 to 1.0 to best-fit the data. The different considered combinations of $a_{2}, a_{3}$ and $a_{4}$ are shown in Table 9.

The matrix scatter diagrams among the dependent variables $\left(P_{\mathrm{DF}}, D_{\mathrm{TM}}\right.$, TSAR) and the new nonlinear functions $\left(f_{1}\right.$ to $f_{13}$ and $f_{1 \text { inv }}$ to $\left.f_{13 \text { inv }}\right)$ are presented in Figure 9. The nonlinearity in the relationships is evident. The scatter plots also demonstrate the linearity that exists in the relationships among the dependent variables $\left(P_{\mathrm{DF}}, \mathrm{TSAR}\right)$ and the transformation functions $\left(f_{1}\right.$ to $\left.f_{13}\right)$. The same can be observed about the dependent variable $\left(D_{\mathrm{TM}}\right)$ and the transformation functions $\left(f_{\text {1inv }}\right.$ to $\left.f_{13 \text { inv }}\right)$. Several trials were
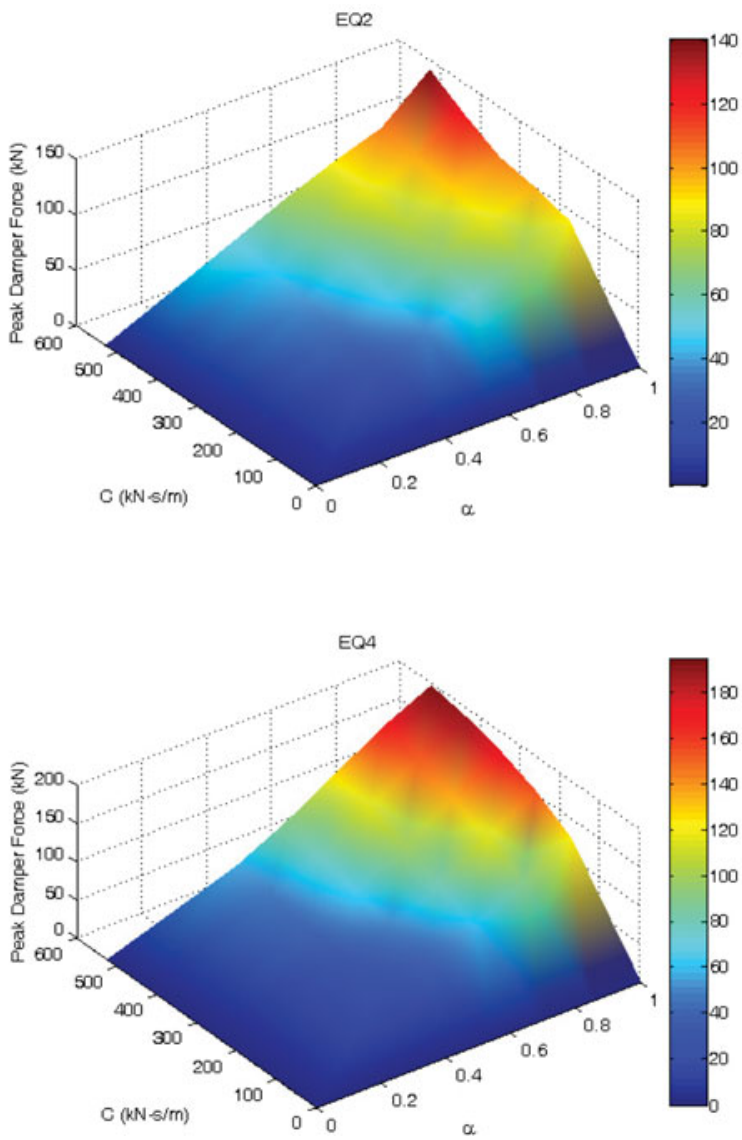

made using SPSS 19.0 (SPSS 2010) to select the bestfit models that could represent the dynamic behavior of the SI system ( $\left.P_{\mathrm{DF}}, D_{\mathrm{TM}}, \mathrm{TSAR}\right)$ through $\left(f_{12}\right.$, $\left.f_{13 \text { inv }}, f_{9}\right)$, respectively, in terms of the four input parameters $\left(C, \alpha\right.$, PGA, $\left.I_{\mathrm{a}}\right)$.

Figure 10 magnifies the scatter plots of ( $P_{\mathrm{DF}}$ vs. $\left.f_{12}\right)$, (TSAR vs. $\left.f_{9}\right)$ as well as ( $D_{\mathrm{TM}}$ vs. $\left.f_{13 \text { inv }}\right)$. From the figure, one can observe that the scatters of $\left(P_{\mathrm{DF}}\right.$ vs. $f_{12}$ ) and (TSAR vs. $f_{9}$ ) are almost constant for all values of the variables, that is, the data points are forming a band with constant width. On the other hand, the scatter of ( $D_{\mathrm{TM}}$ vs. $\left.f_{13 \text { inv }}\right)$ is almost directly proportional to the variables values, that is, the data points are forming a band that becomes wider at a certain rate. These two observations imply that the regression in the former case would be performed with constant variance, whereas non-constant variance would be appropriate in the latter case (Ang, Tang 2007). Addressing this difficulty could be achieved by either: (a) transforming $Y$ to make $\sigma^{2}$ constant, or (b) perform fitting using a more general model that allows $\boldsymbol{\sigma}^{2}$ to vary with $E(y / x)$ - a generalized linear model (e.g. logistic regression, Poisson regression).

In order to stay within the classical linear model, the transformation route is selected for the $D_{\mathrm{TM}}$ parameter. This transformation takes into account the variation of the conditional variance and ex- 

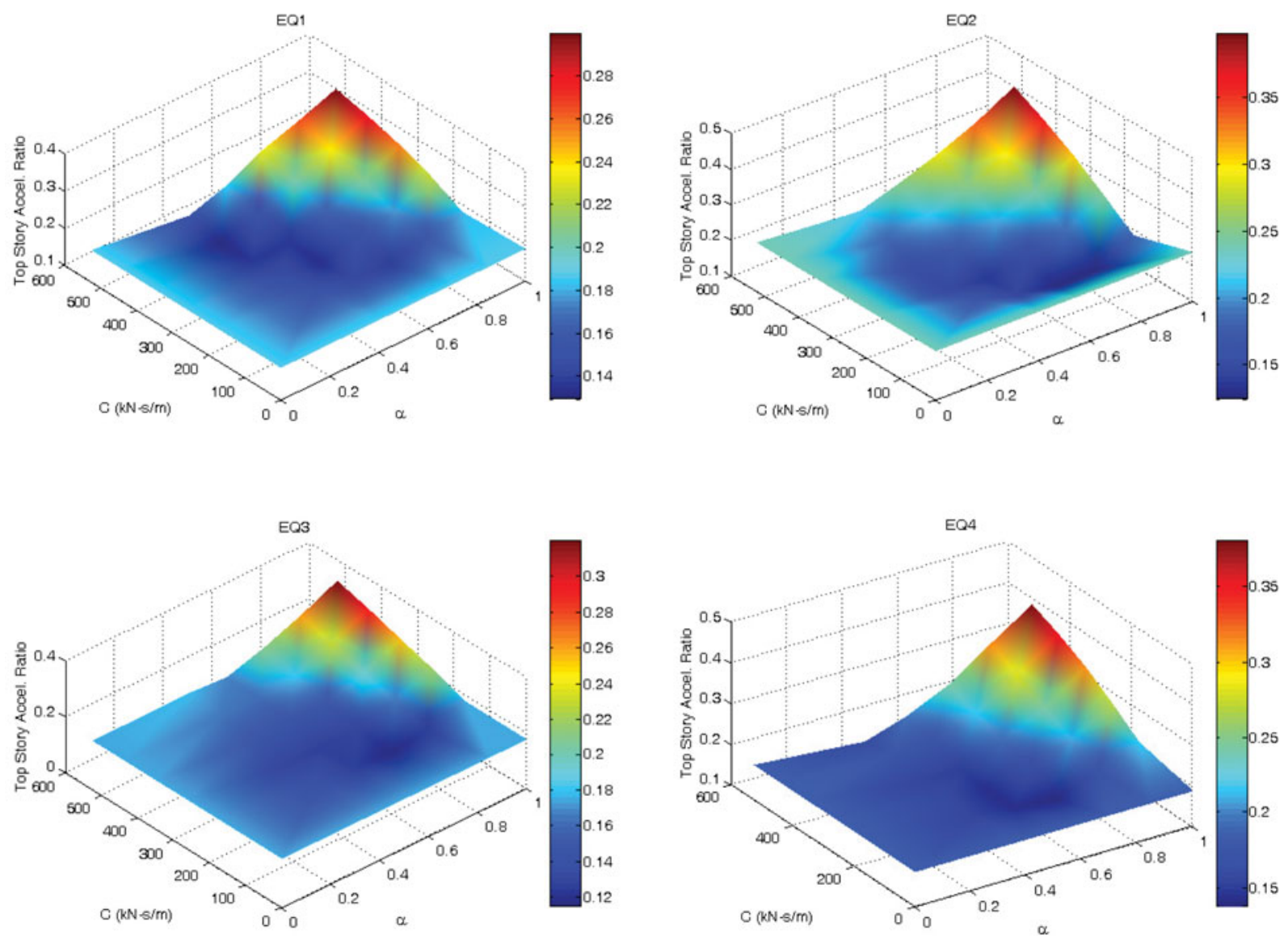

Fig. 6. Top Story Acceleration Ratio (TSAR)

pressed here as $\operatorname{Var}(Y / X=x)=\sigma^{2} g^{2}(x)$, where $\sigma$ is an unknown constant and $g(x)$ is a predetermined function of $x$. This is sometimes referred to as weighted regression. In such cases, it would be reasonable to assign higher weights to data points in regions of small variances than those in regions of large variances (i.e. $w_{i}=1 /\left(g^{2}\left(x_{i}\right)\right)$.

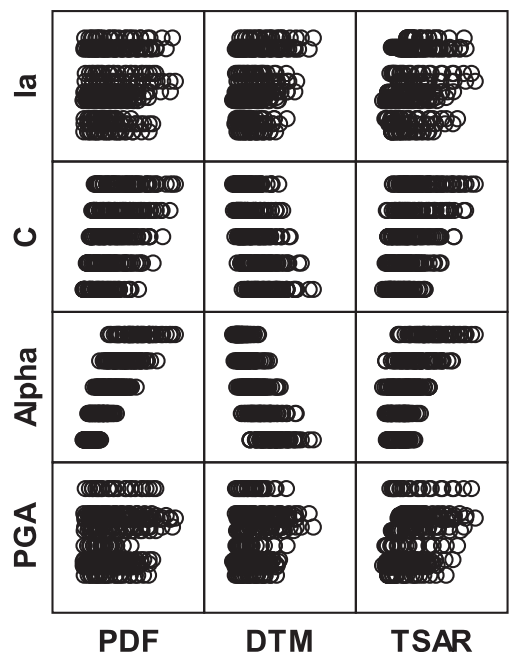

Fig. 7. Matrix scatter plot among three dependent output variables $\left(P_{\mathrm{DF}}, D_{\mathrm{TM}}, \mathrm{TSAR}\right)$ and four independent input variables $\left(C, \alpha\right.$, PGA, $\left.I_{\mathrm{a}}\right)$

Since it could be observed that the scatter of $D_{\mathrm{TM}}$ appears to increase linearly with the $f_{13 \text { inv, }}$ it is assumed that the conditional standard deviation of $D_{\mathrm{TM}}$ increases linearly with $f_{13 \text { inv }}$ too; that is $g(x)=x$, $\operatorname{Var}(Y / X=x)=\sigma^{2} x^{2}$, and $w_{i}=1 / x_{i}^{2}$. In this setup, in addition to the independence and normality of errors, the constant variance assumption is maintained in the

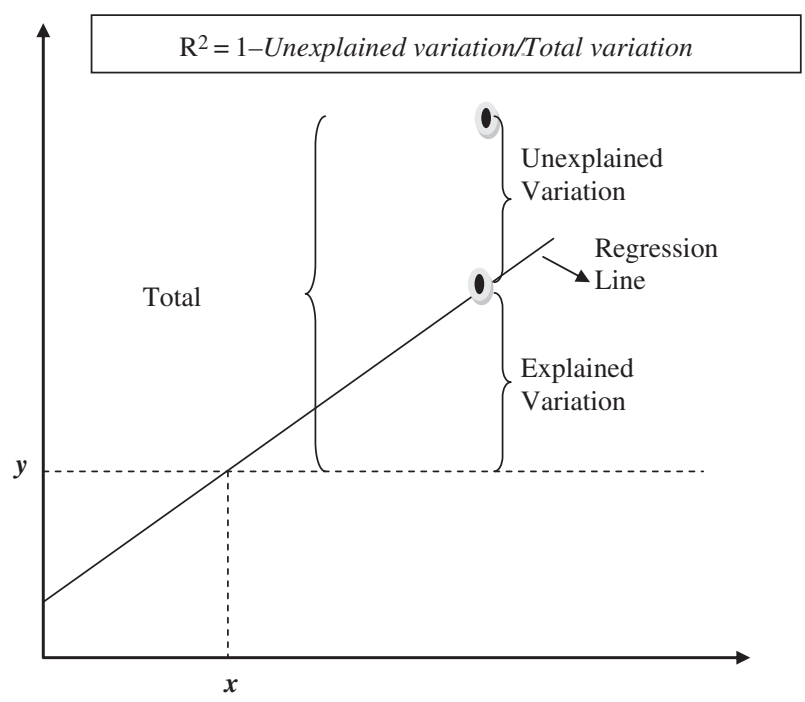

Fig. 8. Definition of the linear regression terms, $R^{2}$ 
Table 8. Linear regression output

\begin{tabular}{|c|c|c|c|c|c|c|}
\hline \multirow[b]{2}{*}{ Model output } & & \multicolumn{5}{|c|}{ Independent variables output } \\
\hline & & Variable, $x i$ & $C$ & $\alpha$ & PGA & $I_{\mathrm{a}}$ \\
\hline \multicolumn{7}{|l|}{ Model for $\left(P_{\mathrm{DF}}\right)$} \\
\hline$R^{2}$ & 0.947 & Coefficient of $x i$ & 0.115 & 166.739 & -100.849 & 2.617 \\
\hline Model $F$-value & 1337.7 & $t$-value & 10.361 & 25.974 & -8.135 & 2.729 \\
\hline Model $F$-significance & 0.000 & $t$-significance & 0.000 & 0.000 & 0.000 & 0.007 \\
\hline \multicolumn{7}{|l|}{ Model for $\left(D_{\mathrm{TM}}\right)$} \\
\hline$R^{2}$ & 0.924 & Coefficient of $x i$ & 0.000 & -0.402 & 0.811 & 0.005 \\
\hline Model $F$-value & 919.2 & $t$-value & -10.668 & -19.045 & 19.921 & 1.644 \\
\hline Model $F$-significance & 0.000 & $t$-significance & 0.000 & 0.000 & 0.000 & 0.101 \\
\hline \multicolumn{7}{|l|}{ Model for (TSAR) } \\
\hline$R^{2}$ & 0.971 & Coefficient of $x i$ & 0.000 & 0.191 & -0.017 & 0.004 \\
\hline Model $F$-value & 2496.9 & $t$-value & 12.073 & 18.576 & -0.835 & 2.452 \\
\hline Model $F$-significance & 0.000 & $t$-significance & 0.000 & 0.000 & 0.405 & 0.015 \\
\hline
\end{tabular}

linear regression models. The outputs from the bestfitting regression trials (with constant and non-constant variance) are listed in Table 10. The forms and coefficients of best-fitting nonlinear models representing the dynamic behavior of the SI system are shown to be physically meaningful, that is, typical trends and intuitive relationships are preserved. For instance, the MRA equation predicting the $P_{\mathrm{DF}}$ has the same mathematical form as Eqn. (1), which describes the physical phenomenon. Also, increasing the damping coefficient $c$, damping exponent $\alpha$ and Arias intensity $I_{\mathrm{a}}$ introduces higher damping levels manifested through a higher damper force $\left(P_{\mathrm{DF}}\right)$. Similarly, higher values of PGA and $I_{\mathrm{a}}$ are expected to increase the induced top story acceleration producing a higher TSAR value. This effect is complimented by the increase in $c$ and $\alpha$ values, which increases the degree of restraint at the base of the structure resulting in less effective SI (higher TSAR values). With the same token, the combined effect of increasing $c$ and $\alpha$ translates into more base restraint, and thus reducing the $D_{\mathrm{TM}}$.

Furthermore, the proposed models demonstrate good correlation: possess high values of $R^{2}$ as well as pass both the $F$ - and the $t$-tests.

\subsubsection{Accuracy of the nonlinear regression models}

The ability of the nonlinear MRA models to mimic the THA results is regarded as its accuracy. The models accuracy is quantified via direct comparison to the SAP2000 results. For Set 1 of the data combinations, the input values are implemented in the MRA models and the corresponding outputs are produced. The direct comparisons of the theoretical SAP2000 results vs. the recalled MRA results are shown in Figures 11-13 for the three response parameters. Good agreement between the results is demonstrated by the graphs. It is worth mentioning here that, apparent increased scatter for higher values of $D_{\mathrm{TM}}$ in Figure 12 is a direct result of the non-constant variance exhibited in the original THA results (Fig. 10, c). This should not be mistakenly regarded as poor prediction capacity for the developed model throughout the entire range values.

\subsubsection{Prediction accuracy of the nonlinear regression models}

For the models adopted in this work, the prediction accuracy is investigated. Data (Set 2) which consist of 50 randomly selected combinations is used to perform three MRA prediction tests. As mentioned earlier, all of the data in this testing set was initially withheld from the MRA. The results of these tests are shown in Figures 14-16.

Models, in general, are descriptions of often highly complex reality that cannot be mathematically

Table 9. Combinations of $a_{2}, a_{3}$ and $a_{4}$ in the transformation form of Eqn. (4)

\begin{tabular}{lcccc}
\hline$f_{i}$ & $a_{2}$ & $a_{3}$ & $a_{4}$ & Form \\
\hline$f_{1}$ & 1 & 1 & 0 & $f_{1}=C(\text { PGA })^{\alpha}$ \\
$f_{2}$ & 1 & 0 & 1 & $f_{2}=C\left(I_{\mathrm{a}}\right)^{\alpha}$ \\
$f_{3}$ & 1 & 0.5 & 0 & $f_{3}=C(\mathrm{PGA})^{0.5 \alpha}$ \\
$f_{4}$ & 1 & 0 & 0.5 & $f_{4}=C\left(I_{\mathrm{a}}\right)^{0.5 \alpha}$ \\
$f_{5}$ to $f_{11}$ & 1 & 1 & 0.3 to $0.9,0.1$ & $f_{5}$ to $f_{11}=C(\mathrm{PGA})\left(I_{\mathrm{a}}\right)^{a_{4} \alpha}$ \\
$f_{12}$ & 1 & 0 & 0.7 & $f_{12}=C\left(I_{\mathrm{a}}\right)^{0.7 \alpha}$ \\
$f_{13}$ & 1 & 0 & 0.8 & $f_{13}=C\left(I_{\mathrm{a}}\right)^{0.8 \alpha}$ \\
$f_{\text {linv }}$ to $f_{13 \text { inv }}$ & -1 & $-a_{3}$ & $-a_{4}$ & $f_{\text {kinv }}=\frac{1}{f_{k}}$, for $k=1,13$ \\
\hline
\end{tabular}




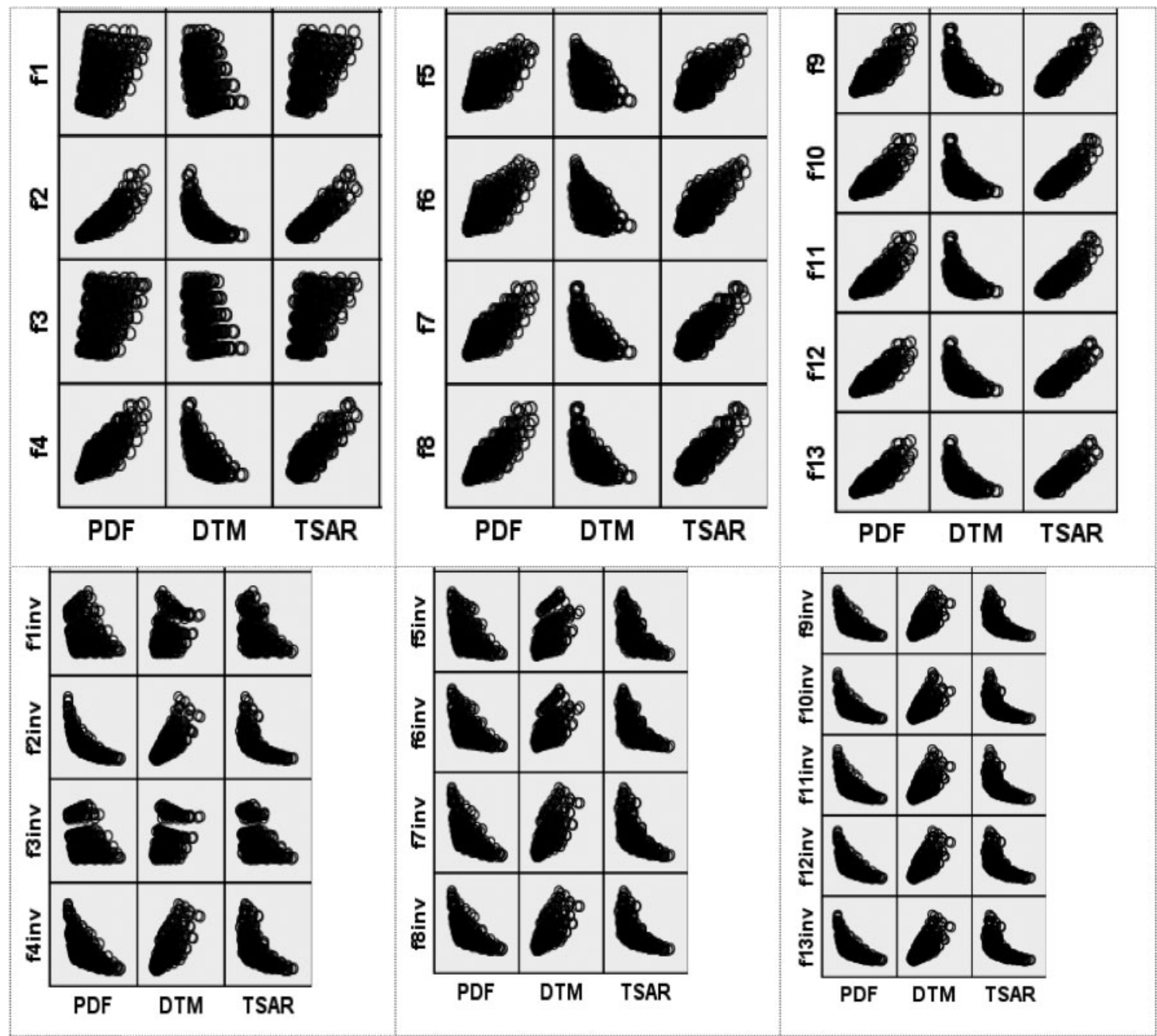

Fig. 9. Matrix scatter plot among three dependent variables $\left(P_{\mathrm{DF}}, D_{\mathrm{TM}}, \mathrm{TSAR}\right)$ and the new nonlinear functions $\left(f_{1}\right.$ to $f_{13}$ and $f_{\text {linv }}$ to $f_{13 \text { inv }}$ )

expressed in a perfect manner, that is, by nature all models are simply partial descriptions of the modeled phenomena. With that fact in mind, the results in Figures $14-16$ are considered reasonable, since perfect models are not achievable, only adequate ones are. Accepting this limitation does not mean the conclusions reached would be incorrect. The formulated models should attempt to closely represent the natural physical phenomenon.

To demonstrate adequacy, the proposed models should show high correlation (high values of $R^{2}$ ), as well as pass certain tests such as the $F$ - and the $t$-tests. In general, the closer the predicted values are to the regression line, the larger $R^{2}$ would be. The $P_{\mathrm{DF}}, D_{\mathrm{TM}}$, and TSAR regression models in Table 10 have high values of $R^{2}(0.939,0.879$, and 0.941 , respectively) and pass the $F$ - and the $t$-tests. The adequate closeness of the points in Figures 14-16 to the equality lines indicates the validity of the MRA models as appropriate prediction tools.

\subsubsection{Worked-out example to demonstrate the use of} MRA models

Problem:

Design an SI system for a three-story essential facility in a NF location in California (maximum Arias intensity $I_{\mathrm{a}}=10.7 \mathrm{~m} / \mathrm{s}$, PGA $=0.84 \mathrm{~g}$ ). The target natural period for the isolated structure is estimated to be $2.5 \mathrm{~s}$.

Solution:

1) Determine whether or not supplemental damping is required.

Since the Time-History records used to analyze an MDOF system are scaled to match the design response spectrum, a Single-DegreeOf-Freedom (SDOF) can be used for preliminary analysis $\Rightarrow$ Using the MCE response spectrum in Figure 2b, the 5\% damped spectral acceleration $S_{a}$ for a SDOF with a natural period $T_{n}=2.5 \mathrm{~s}$ is approximately $0.58 \mathrm{~g}$. 


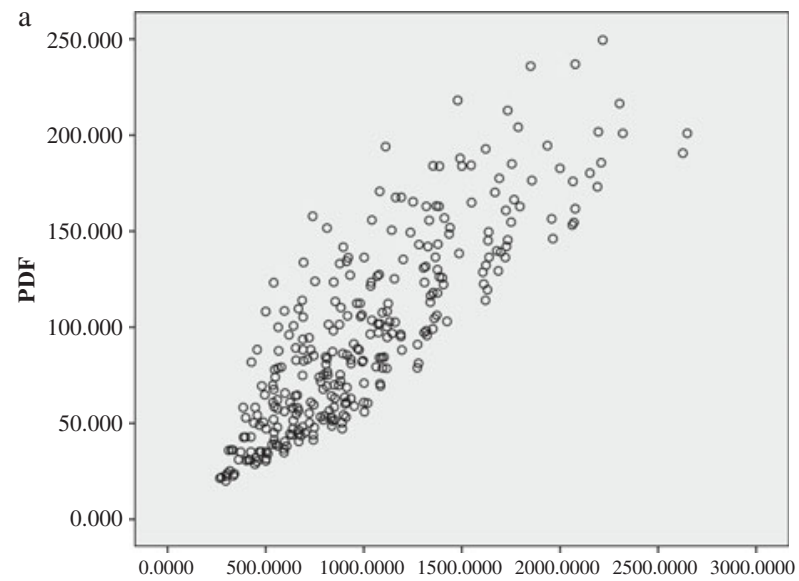

f12
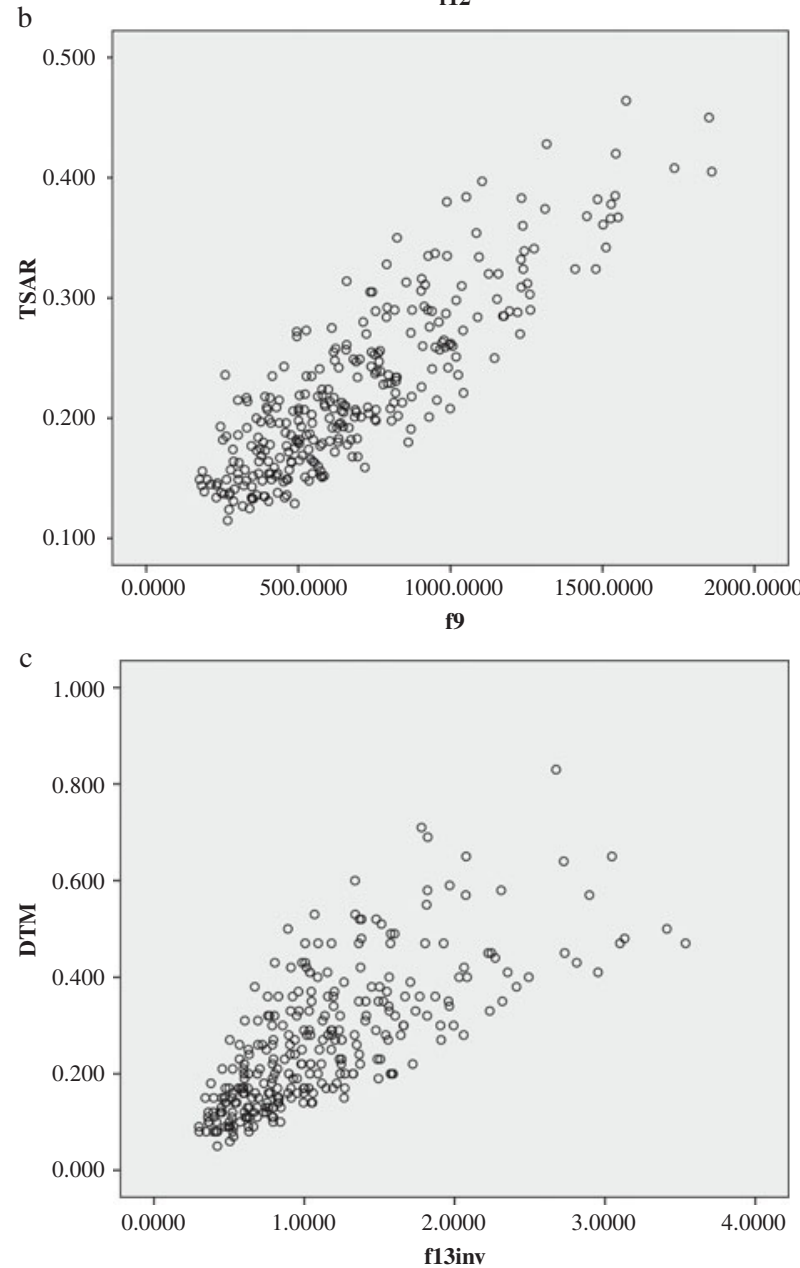

Fig. 10. Magnified scatter plots of: (a) $P_{\mathrm{DF}}$ vs. $f_{12}$, (b) TSAR vs. $f_{9}$, (c) $D_{\mathrm{TM}}$ vs. $f_{13 \text { inv }}$

The spectral displacement $S_{\mathrm{d}}(5 \%)=S_{a} / \omega_{\mathrm{n}}^{2}=$ $0.58 \times 9.81 / 2.513^{2}=2.26 \mathrm{~m}$.

Assuming HDR isolators are to be used $\Rightarrow$ expected supplemental damping level $=15 \%$. $S_{\mathrm{d}}(15 \%)=S_{\mathrm{a}}(5 \%) / B_{\mathrm{M}}$; where $\left(B_{\mathrm{M}}\right)$ is the damping coefficient used to modify dynamic response based on the expected damping ratio. $\left(B_{\mathrm{M}}\right)$ can be obtained from Table A-16-C of Appendix 16A in the CBC (2010).
For a damping ratio of $15 \% \Rightarrow B_{\mathrm{M}}=1.35$. $S_{\mathrm{d}}(15 \%)=2.26 / 1.35=1.68 \mathrm{~m} \quad(66$ in $) \Rightarrow$ $D_{\mathrm{TM}}=S_{\mathrm{d}}=1.68 \mathrm{~m}$ (too large for a three-story building) $\Rightarrow$ supplemental damping is required to reduce the $D_{\mathrm{TM}}$.

Since dampers will be used $\Rightarrow$ opt for NR bearings combined with VFD.

2) Select a suitable SI system by considering different combinations of $\mathrm{C}$ and $\alpha$ values in evaluating the three basic performance descriptors $\left(P_{\mathrm{DF}}, D_{\mathrm{TM}}, \mathrm{TSAR}\right)$. The considered combinations and corresponding results using the MRA models and their verifications using THA are presented in Table 11 .

3) After the MRA models for the $\left(P_{\mathrm{DF}}, D_{\mathrm{TM}}\right.$, TSAR) have been verified throughout the range of input variables, the designer can choose to minimize one parameter on the expense of another to reach a reasonable trade-off for the expected performance. The final system chosen should ultimately be verified against THA. Samples of such runs are shown in Table 12. Comparing the responses to the considered combinations in Tables 11 and 12 , the $(C=219, \alpha=0.45)$ combination gives a reasonable trade-off among the ( $\left.P_{\mathrm{DF}}, D_{\mathrm{TM}}, \mathrm{TSAR}\right)$. Consequently, the $(C=219, \alpha=0.45)$ combination is selected for the SI system.

\section{Summary and conclusions}

The feasibility of using MRA to model and predict the dynamic behavior of Seismic-Isolated (SI) systems was investigated. THA was performed using SAP2000 for three MDOF systems representing a typical seismicisolated structure with a natural period of vibration equal to $2.5 \mathrm{~s}$. Two ensembles of seven ground motion records representing two hazard levels (DBE and MCE) and return periods (475 and 950 years) were used. The range of the SI system properties covered several feasible solutions comparable to the state-ofthe-practice designs. Three key response parameters were selected to be modeled using MRA, namely; $D_{\mathrm{TM}}, P_{\mathrm{DF}}$, and TSAR of the isolated structure compared to the fixed-base structure. The response parameters, as well as the characteristics of the ground motions were utilized to develop several MRA models. For each of the key response parameters, the bestfitting MRA model was selected. The design process of SI systems is iterative, complex and requires considering many feasible alternatives. Moreover, the most widely used analysis tool, the nonlinear THA, is very expensive in terms of CPU time which adds another layer of complexity to the situation. Therefore, simplifying techniques are extremely valuable especially at the preliminary design stages. 
Table 10. Nonlinear regression output

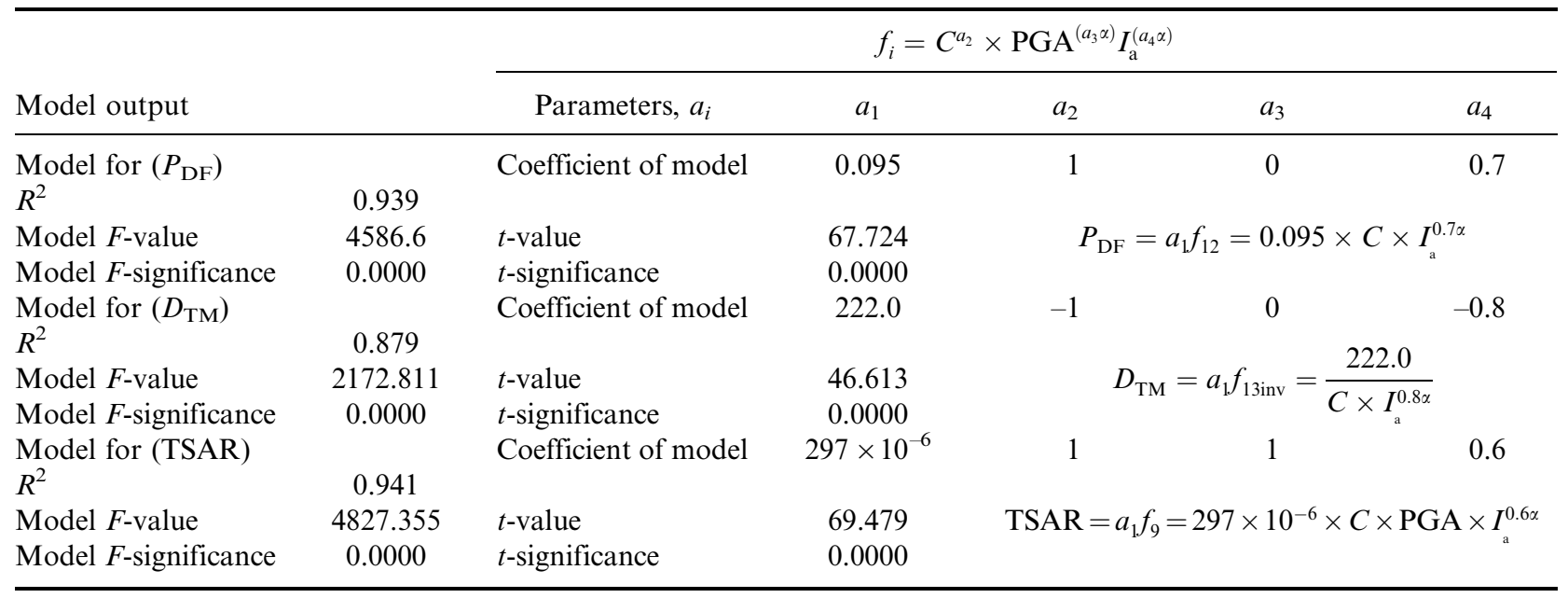

In this investigation, it was demonstrated that the MRA modeling is a strong candidate to accompany, if not replace, the nonlinear THA. Once MRA models are developed through performing rigorous nonlinear THA, such as the presented work, several design options of SI systems can be easily selected and compared. Since the use of MRA models to evaluate the key response parameters is significantly simpler than performing THA, much more feasible solutions can be readily investigated and compared. This can be particularly valuable in the early design stages of SI systems utilizing the NRB-VFD combination as demonstrated in the practical design example in Section 2.2.7. Although the developed MRA models are based on the analysis of a five-story building, the three-story building example demonstrates the applicability to different building heights and configurations. This is attributed to the fact that the dynamic response of seismically-isolated structures is mainly dominated by the fundamental modes of vibration; that is, the behavior is SDOF-like since higher modes shapes are increasingly supressed as a result of the supports flexibility and relatively higher damping levels.

Furthermore, the relative simplicity and explicitness of the derived expressions qualifies them to be used in multi-objective optimization formulations for the key response parameters. The presented methodology can be extended to other SI systems, structures with other natural frequencies, as well as more earthquake records to produce MRA models representing a wider range of structures.

Finally, it should be mentioned that the traditional best-fit measures (e.g. $R^{2}$ ) cannot be solely relied upon in selecting the best MRA model. The MRA mathematical representation should provide sufficient meaningfulness and compatibility with the modeled physical phenomena before being accepted as the most suitable representation.

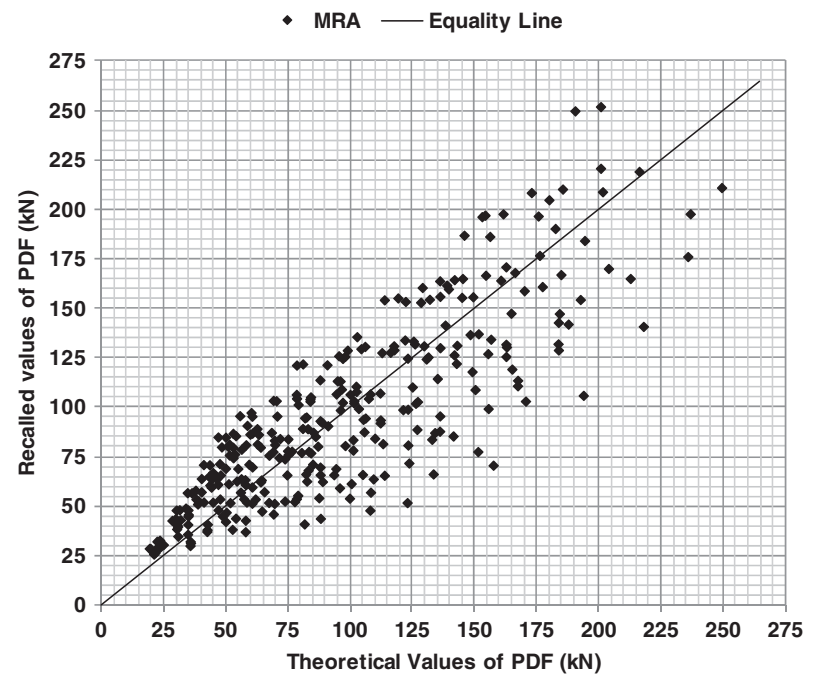

Fig. 11. Recalled $P_{\mathrm{DF}}$ values by multiple nonlinear regression vs. theoretical data (set1)

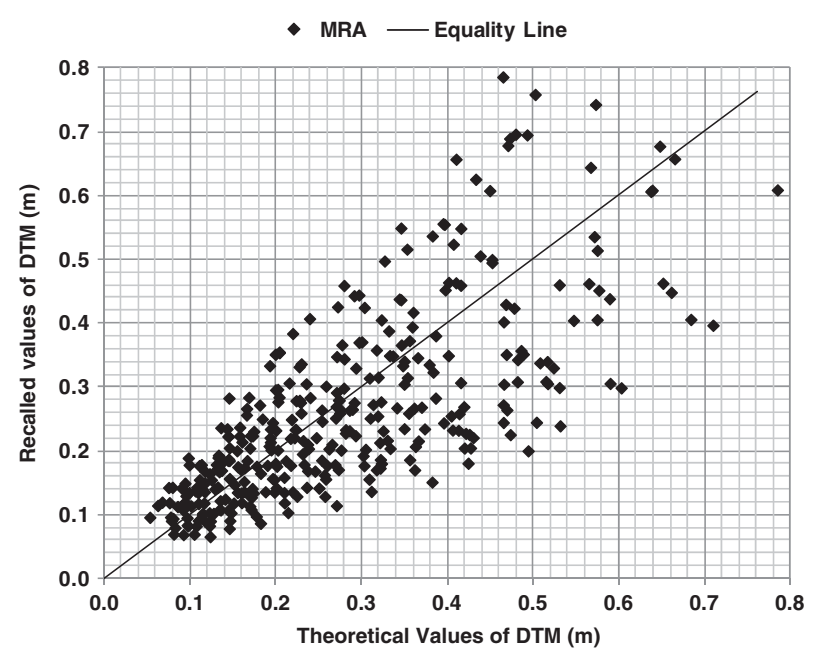

Fig. 12. Recalled $D_{\mathrm{TM}}$ values by multiple nonlinear regression vs. theoretical data (Set 1) 


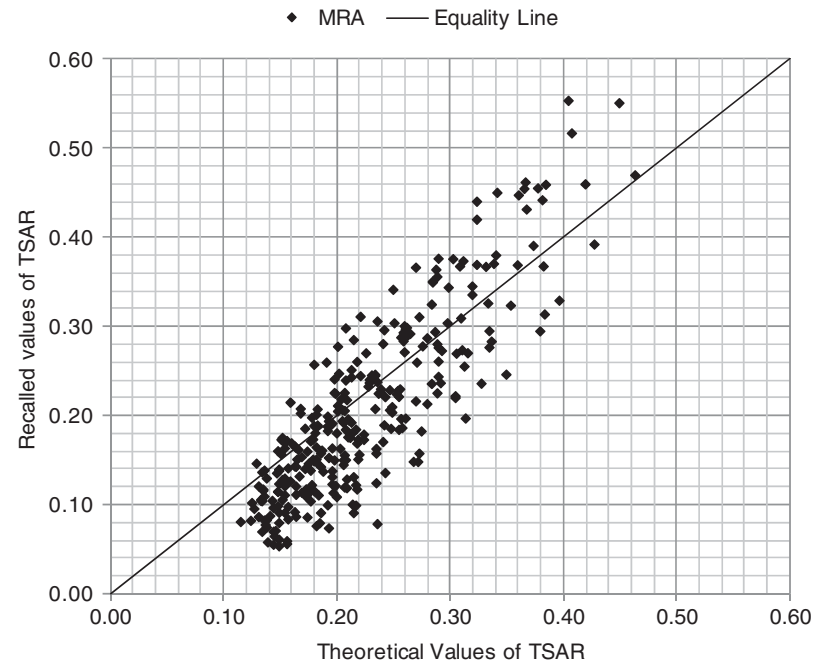

Fig. 13. Recalled TSAR values by multiple nonlinear regression vs. theoretical data (Set 1)

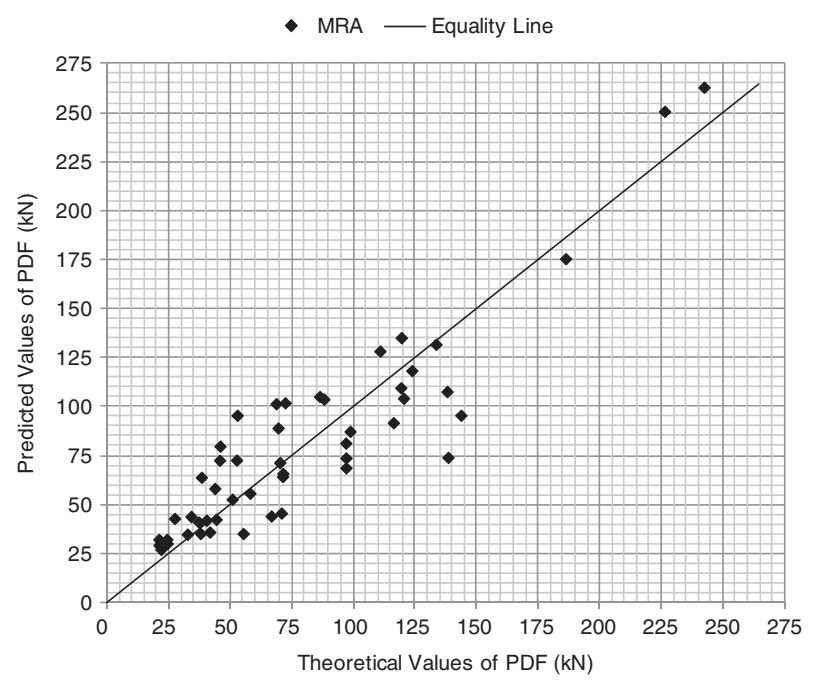

Fig. 14. Predicted $P_{\mathrm{DF}}$ values by multiple nonlinear regression vs. theoretical data (Set 2)

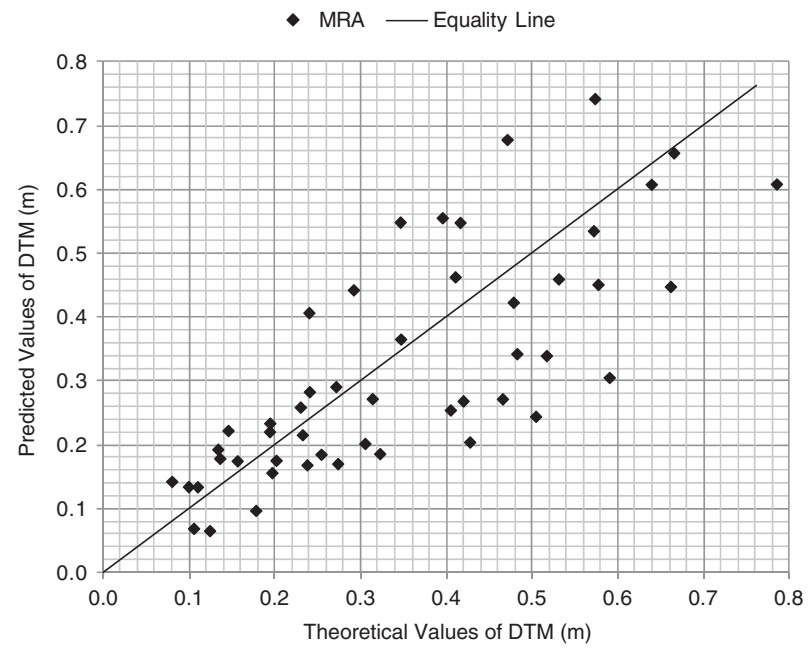

Fig. 15. Predicted $D_{\mathrm{TM}}$ values by multiple nonlinear regression vs. theoretical data (Set 2)

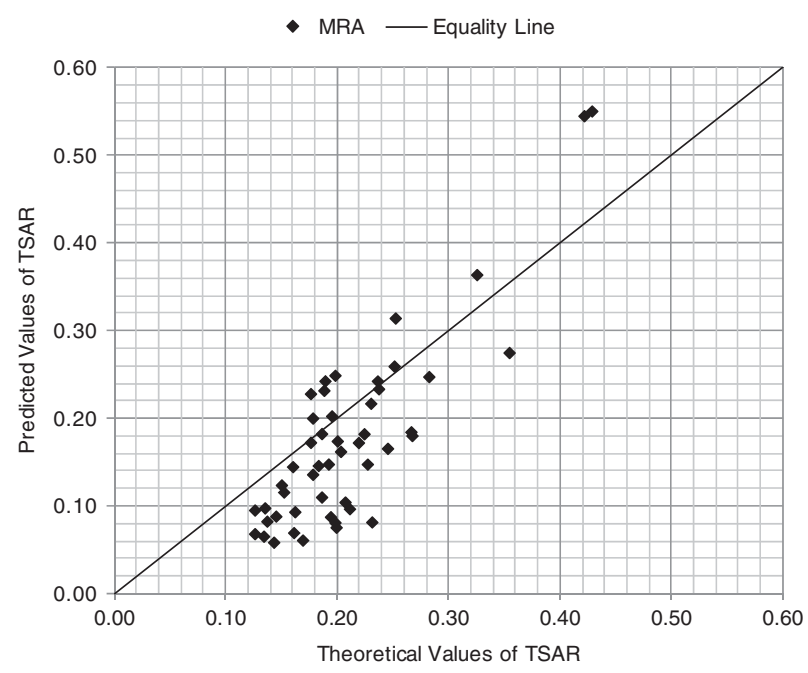

Fig. 16. Predicted TSAR values by multiple nonlinear regression vs. theoretical data (Set 2)

Table 11. VFD system property combinations and corresponding responses using MRA \& THA

\begin{tabular}{lllll}
\hline$C(\mathrm{kN}-\mathrm{s} / \mathrm{m})$ & $\alpha$ & \multicolumn{1}{c}{ Response by MRA } & Response by THA & Deviation $(\%)$ \\
\hline 219 & 0.45 & $D_{\mathrm{TM}}=\frac{222}{219(10.7)^{0.8} \times 0.45}=0.43 \mathrm{~m}$ & $0.48 \mathrm{~m}$ & 10.4 \\
306 & 0.625 & $\mathrm{TSAR}=\left(297 \times 10^{-6}\right)(306)(0.84)(10.7)^{0.6 \times 0.625}=0.19$ & 0.22 & 13.6 \\
482 & 0.9 & $P_{\mathrm{DF}}=0.095(482)(10.7)^{0.7 \times 0.9}=204 \mathrm{KN}$ & $228 \mathrm{kN}$ & 10.5 \\
\hline
\end{tabular}

Table 12. VFD system property combinations and corresponding responses using MRA

\begin{tabular}{lll}
\hline$C(\mathrm{kN}-\mathrm{s} / \mathrm{m})$ & $\alpha$ & \multicolumn{1}{c}{ Response by MRA } \\
\hline 306 & 0.625 & $D_{\mathrm{TM}}=\frac{222}{306(10.7)^{0.8 \times 0.625}}=0.22 \mathrm{~m}$ \\
482 & 0.9 & $D_{\mathrm{TM}}=\frac{222}{482(10.7)^{0.8 \times 0.9}=0.08 \mathrm{~m}}$ \\
219 & 0.45 & $\mathrm{TSAR}=\left(297 \times 10^{-6}\right)(219)(0.84)(10.7)^{0.6 \times 0.45}=0.10$ \\
482 & 0.9 & $\mathrm{TSAR}=\left(297 \times 10^{-6}\right)(482)(0.84)(10.7)^{0.6 \times 0.9}=0.43$ \\
219 & 0.45 & $P_{\mathrm{DF}}=0.095(219)(10.7)^{0.7 \times 0.45}=44 \mathrm{KN}$ \\
306 & 0.625 & $P_{\mathrm{DF}}=0.095(306)(10.7)^{0.7 \times 0.625}=82 \mathrm{KN}$ \\
\hline
\end{tabular}




\section{References}

AlHamaydeh, M.; Hussain, S. 2010. Innovative design of a seismically-isolated building with supplemental damping, in Proc. of the 14th European Conference on Earthquake Engineering (14ECEE), 30 August-3 September, 2010, Ohrid, Republic of Macedonia, 823-831.

Al Satari, M.; Abdalla, J. 2009. Optimization of a baseisolation system consisting of natural rubber bearings and fluid viscous dampers, in Proc. of the 11th World Conference on Seismic Isolation, Energy Dissipation and Active Vibration Control of Structures, 17-21 November, 2009, Guangzhou, China, 524-539.

Ang, H. S.; Tang, W. H. 2007. Probability concepts in engineering, emphasis on applications to civil and environmental engineering. 2nd ed. New Jersey, USA: Wiley. $420 \mathrm{p}$.

Arias, A. 1970. A measure of earthquake intensity, in Hensen, R. J. (Ed.). Seismic design for nuclear power plants. Cambridge, MA: MIT press, 438-483.

Chopra, A. K.; Chintanapakdee, C. 2001. Comparing response of SDF systems to near-fault and far-fault earthquake motions in the context of spectral regions, Earthquake Engineering and Structural Dynamics 30(12): 1769-1789. http://dx.doi.org/10.1002/eqe.92

Computers and Structures, Inc. (CSI). 2010. SAP2000 reference manual. California: Berkeley 632 p..

El-Shaarawi, A.; Walter, P. 2002. Nonlinear regression, in Smyth, G. K. (Ed.). Encyclopedia of Environmetrics. Chichester: John Wiley \& Sons, Ltd., 1405-1411.

Hussain, S. 1994. Performance of base isolated buildings in the northridge earthquake, in Seismic Base Isolation State of the Practice Seminar, 21 May, 1994. Structural Engineers Association of Southern California, USA, $125-134$.

Hussain, S.; Al Satari, M. 2007a. Design of a seismic isolation system with supplemental viscous damping for a near-fault essential services facility, in Proc. of the 76th SEAOC Annual Convention, 26-29 September, 2007, Squaw Creek, 153-162.

Hussain, S.; Al Satari, M. 2007b. Viscous-damped seismic isolation system for a near-fault essential services facility, in Proc. of the 10th World Conference on Seismic Isolation, Energy Dissipation and Active Vibration Control of Structures, 27-30 May, 2007, Istanbul, Turkey, 652-665.

Hussain, S.; Al Satari, M. 2008. Innovative design of a seismic isolation supplemental viscous damping systems of an essential services facility in a near-fault region, in Proc. of the 14th World Conference on Earthquake Engineering, 12-17 October, 2008, Beijing, China, 956-964.

Hussain, S.; Asher, J.; Ewing, B. 1993. Seismic base isolation design for the San Bernardino County Medical Center replacement project, in Structural Engineering in Natural Hazards Mitigation: Proceedings of the Structures Congress, American Society of Civil Engineers, April, 1993, New York, USA, 1: 760-765.

Hussain, S.; Retamal, E. 1994. A hybrid seismic isolation system - isolators with supplemental viscous dampers, in Proc. of the First World Conference on Structural Control, 3-5 August, 1994, Los Angeles, USA, 3: FA253-FA2-62.

International Conference of Building Officials (ICBO). 2010. California building code, structural engineering provisions. International Conference of Building Officials (ICBO), Whittier, California, vol. 2: 16-21-16-45.

Jangid, R. S. 2005. Optimum friction pendulum system for nearfault motions, Engineering Structures 27(3): 349-359. http://dx.doi.org/10.1016/j.engstruct.2004.09.013

Jangid, R. S.; Kelly, J. M. 2001. Base isolation for near-fault motions, Earthquake Engineering \& Structural Dynamics 30(5): 691-707. http://dx.doi.org/10.1002/eqe.31

Kani, N.; Nishikawa, T. 2010. Recent trends of seismically isolated structures in Japan, in 2010 Seismic Symposium of Japan Society of Seismic Isolation. Presentation. Tokyo, Japan, 25-45.

Kelly, J. M. 1997. Earthquake-resistant design with rubber. 2nd ed. London: Springer-Verlag. 243 p.

Kelly, J. M.; Leitmann, G.; Soldatos, A. G. 1987. Robust control of base-isolated structures under earthquake excitation, Journal of Optimization Theory \& Applications 53(2): 159-180. http://dx.doi.org/10.1007/BF00939213

Macrae, G. A.; Morrow, D. V.; Roeder, C. W. 2001. Nearfault ground motion effects on simple structures, Journal of Structural Engineering 127(9): 996-1004. http://dx.doi.org/10.1061/(ASCE)0733-9445(2001)127: 9(996)

Makris, N.; Black, C. J. 2004. Dimensional analysis of bilinear oscillators under pulse-type excitations, Journal of Engineering Mechanics 130(9): 1019-1031. http://dx.doi.org/10.1061/(ASCE)0733-9399(2004)130: 9(1019)

Matsagar, V. A.; Jangid, R. S. 2005. Viscoelastic damper connected to adjacent structures involving seismic isolation, Journal of Civil Engineering and Management 11(4): 309-322. http://dx.doi.org/10.1080/13923730.2005.9636362

Naeim, F.; Kelly, J. M. 1999. Design of seismic isolated structures: From theory to practice. New Jersey, USA: John Wiley \& Sons. 304 p.

Providakis, C. P. 2008. Effect of LRB isolators and supplemental viscous dampers on seismic isolated buildings under near-fault excitations, Engineering Structures 30(5): 1187-1198. http://dx.doi.org/10.1016/j.engstruct.2007.07.020

Providakis, C. P. 2009. Effect of supplemental damping on LRB and FPS seismic isolators under near-fault ground motions, Soil Dynamics and Earthquake Engineering 29(1): 80-90. http://dx.doi.org/10.1016/j.soildyn.2008.01.012

Rodriguez-Marek, A. 2000. Near fault seismic site response. PhD Thesis. Civil Engineering, University of California, Berkeley.

Skinner, R. I.; Robinson, W. H.; McVerry, G. H. 1993. An introduction to seismic isolation. London: John Wiley and Sons. $354 \mathrm{p}$.

SPSS. 2010. SPSS ver. 19.0 reference manual. Chicago, Illinois, USA: IBM. 
Mohammad H. ALHAMAYDEH. Assistant Professor of Civil Engineering in the College of Engineering at the American University of Sharjah (AUS), Sharjah, UAE. He received his BSc and MSc degrees in Civil/Structural Engineering from the Jordan University of Science and Technology (JUST), Irbid, Jordan in 1995 and 1999 , respectively. In 2005, he received his $\mathrm{PhD}$ in Structural/Earthquake Engineering from the University of Southern California (USC), Los Angeles, California. Prior to his academic career, he was an active member of the Structural Engineers Association of California (SEAOC) as a consultant engineer in Los Angeles, California. His research interests include nonlinear structural dynamic response analysis and modeling, passive control and supplemental damping devices, computer-aided design and simulation, nonlinear finite element methods as well as soil-structureinteraction.

Samer A. BARAKAT. Professor of Civil Engineering at the Department of Civil and Environmental Engineering at the University of Sharjah, Sharjah, UAE. He received his PhD degree from University of Colorado at Boulder, USA in 1994 for his thesis research in structural system reliability with applications to bridge analysis, design and optimization. He obtained his Master degree in Structural Engineering from Jordan University of Science and Technology, Jordan in 1989 and his Bachelor degree in Civil Engineering/Structural Engineering from Yarmouk University, Jordan, in 1984. His research interests include structural reliability, reliability-based design and optimization, composite materials and retrofitting of structures, neural networks and seismic risk structural assessment.

Farid H. ABED. Associate Professor of Civil Engineering in the College of Engineering at the American University of Sharjah (AUS), Sharjah, UAE. He received his BSc degree from the University of Technology, Baghdad, Iraq in 1992 and MSc degree in Civil/Structural Engineering from the Jordan University of Science and Technology (JUST), Irbid, Jordan in 1997. He received his PhD in Structures/Mechanics from the Louisiana State University (LSU), Baton Rouge, USA in 2005. His research interests include computational solids and structural mechanics, mechanics of composite materials and structures, constitutive modeling, damage mechanics, and nonlinear finite element analysis. 